\title{
Paris emission inventory diagnostics from ESQUIF airborne measurements and a chemistry transport model
}

\author{
R. Vautard, ${ }^{1}$ D. Martin, ${ }^{2,3}$ M. Beekmann, ${ }^{4}$ P. Drobinski, ${ }^{4}$ R. Friedrich,${ }^{5}$ A. Jaubertie,${ }^{6}$ \\ D. Kley, ${ }^{7}$ M. Lattuati, ${ }^{6}$ P. Moral, ${ }^{2}$ B. Neininger, ${ }^{8}$ and J. Theloke ${ }^{5}$
}

Received 25 July 2002; revised 4 October 2002; accepted 3 December 2002; published 13 August 2003.

[1] During the Atmospheric Pollution Over the Paris Area (ESQUIF) experiment a series of airborne measurements were collected in the vicinity of the city of Paris during smog episodes. They are used in combination with an air quality photochemical model in order to diagnose uncertainties in the current emission inventory. Diagnostics are made by comparing simulated with observed concentrations for nitrogen oxides, carbon monoxide, and primary hydrocarbons, taking into account the chemistry and transport processes of these compounds. An emphasis is put on the uncertainty of the results, taking into account the finiteness of the measurement samples, possible errors in the model transport, and chemistry and measurement errors. We examine, in particular, possible sources of bias in the model. For instance, we show that boundary layer depth is underestimated by at most $30 \%$ on average. However, sensitivity experiments showed that these model biases, taken individually, cannot alter the qualitative aspects of our results. Only a conspiracy of these biases could possibly shift all our diagnostics toward significantly different results. There is reasonable consistency between simulated and measured concentrations. $\mathrm{NO}_{y}$ simulations agree with measured concentrations to within 35\%; CO concentrations agree to within a factor of 2 . There are significant underestimations and overestimations in some individual primary hydrocarbons. However, the total mass and reactivity of the measured hydrocarbon mixture, which accounts for only about half of the total emitted mass, agree with modeled values to within an estimated uncertainty of $40 \%$. The analysis of results provides clues for improving emission inventories. It is found, for instance, that temperature dependence, which is not considered here, can be a key factor and that hydrocarbon emissions from solvent use may suffer from inaccurate totals or speciation. Another source of uncertainties may be the temporal or spatial distributions of solvent activities. INDEX TERMS: 0315 Atmospheric Composition and Structure: Biosphere/atmosphere interactions; 0317 Atmospheric Composition and Structure: Chemical kinetic and photochemical properties; 0322 Atmospheric Composition and Structure: Constituent sources and sinks; 0345 Atmospheric Composition and Structure: Pollution - urban and regional (0305); KEYWORDS: emissions, airborne measurements, photochemistry, NMVOC melting

Citation: Vautard, R., et al., Paris emission inventory diagnostics from ESQUIF airborne measurements and a chemistry transport model, J. Geophys. Res., 108(D17), 8564, doi:10.1029/2002JD002797, 2003.

\footnotetext{
${ }^{1}$ Laboratoire de Météorologie Dynamique, Ecole Polytechnique, Paris, France.

${ }^{2}$ Laboratoire des Sciences du Climat et de l'Environnement, Gif-surYvette, France.

${ }^{3}$ Now at Météo France, Paris, France.

${ }^{4}$ Service d'Aéronomie, Centre National de la Recherche Scientifique, Paris, France.

${ }^{5}$ Institute of Energy Economics and the Rational Use of Energy, University of Stuttgart, Stuttgart, Germany.

${ }^{6}$ AIRPARIF, Paris, France.

${ }^{7}$ Institute for Chemistry of the Polluted Atmosphere, Forschungszentrum, Jülich, Germany.

${ }^{8}$ MetAir, Menzingen, Switzerland.

Copyright 2003 by the American Geophysical Union. 0148-0227/03/2002JD002797
}

\section{Introduction}

[2] A mandatory condition for elaborating efficient control strategies of atmospheric pollution at an urban scale is to have an accurate knowledge of the primary emissions. The construction of inventories of emissions is a tremendous task which involves a robust partnership between different organizations whose objectives may diverge: environmental agencies, industries, or teams in charge of road transport modeling. This construction is always achieved by a mix of the "bottom-up" approach, summing up known individual sources, and of the "top-down" approach, distributing in space and time global quantities such as consumption of gasoline or solvents. 
[3] The knowledge of the sources is uncertain in all aspects, in time and space distribution and in total yearly mass, and in most cases the uncertainty cannot even be quantified in an objective manner. However, recently, the uncertainty estimation problem has been tackled in several studies [Hannah et al., 1998; Kühlwein and Friedrich, 2000]. The approach generally consists of integrating uncertainties of individual sources. Another possibility is to compare results from different emission models in order to obtain an order of magnitude of the uncertainty due to methods.

[4] In all these cases, uncertainty estimates are obtained using current knowledge about emissions but cannot integrate what is not known about the emissions. An alternative way of proceeding is to use ambient pollutant concentrations and to evaluate the degree of consistency between these measured concentrations and those obtained from the inventoried emissions after physical (transport/mixing/deposition) and chemical transformations. This receptor-oriented approach, which has been used several times [Goldan et al., 1995; Kleinman et al., 1998] (see also Trainer et al. [2000] for an exhaustive review), also suffers from various problems. First, the space and time distribution of emissions can hardly be diagnosed since ambient concentrations are integral quantities. Only global diagnostics can therefore be carried out. Second, the transformation from emissions to concentrations is the result of chemistry, transport, and mixing processes which also contain many uncertainties. These uncertainties can obscure the interpretation of measurements.

[5] Some studies use a "Lagrangian approach" by simply transporting emitted quantities with the wind down to the receptor point [e.g., Kramp and Volz-Thomas, 1997; Lehning, 1998; Corsmeier et al., 2002; Becker et al., 2002], while others make use of full three-dimensional air quality models [see e.g., Harley and Cass, 1995; Chang et al., 1997; Mannschreck et al., 2002; Mendoza-Dominguez and Russel, 2001]. In the study by Mendoza-Dominguez and Russel [2001] an attempt is made to diagnose emissions increments that would be necessary to make model simulations and observations best fit using a fully objective technique, the four-dimensional variational assimilation.

[6] Following the same objective, this article intends to use airborne Atmospheric Pollution Over the Paris Area (ESQUIF) [Menut et al., 2000] measurements (instead of surface measurement in most previous studies) and an air quality model in order to assess the emission inventory available over a limited, regional area around Paris city. The ESQUIF field campaign took place during the summers of 1998 and 1999.

[7] The principal question we address is whether measurements taken in such a campaign do provide enough information to make reliable inferences about the emission inventory given the fact that the model and measurements are imperfect. In particular, we make extensive model/ observation comparisons in order to assess uncertainties due to the model itself or to the finiteness of the measurement samples. The completeness of this study lies in the fact that the most important pollutants are considered: nitrogen oxides $\left(\mathrm{NO}_{y}\right)$, carbon monoxide (CO), and individual nonmethane volatile organic compounds (NMVOCs). However, the study has the limitations inherent to most diagnostic approaches using observations, that is, we are not able to evaluate the space and time distribution of emissions. Another limitation comes from the number of measured species for NMVOCs; here $\sim 50 \%$ of the total NMVOC mass is considered.

[8] The advantage of using airborne measurements lies in their believed higher representativeness compared with ground-based observations since the latter are often taken within a layer where large vertical or horizontal gradients occur (especially for primary species). However, this advantage is compensated by the limited amount of acquired data. Moreover, the model coarse vertical resolution does not allow a sharp representation of the sharp concentration gradients near the ground. During ESQUIF, several intensive observation periods (IOPs) throughout summer 1999 took place, so the number of studied days is still relatively large; the measurements used here cover 7 days during the months of June and July, so we hope to represent the variability of atmospheric situations leading to degradation of air quality.

[9] The Paris area has many advantages for the purpose of this study. First, it has a large central urban area with several millions of inhabitants, so a strong pollution signal is often observed. Second, the urban area is located relatively far from other major or intermediate cities, so the pollution plume coming from the urban area is easy to detect. Finally, Paris is located on an almost flat terrain and is far from any coastal area, so mesoscale dynamical effects are supposedly minor.

[10] The methodology used here consists of comparing measured and simulated mixing ratios in order to make diagnostics of the emission inventory. The chemistry transport model (CTM) uses the inventory to calculate mixing ratios at the receptor locations. We discuss all possible sources of error in the diagnostics (sampling uncertainty, model errors, etc.).

[11] The measurements are described in section 2, and the inventory and the chemistry transport model are described in section 3. In section 4, we compare the spatial structure of the simulated and observed pollution plumes over the IOP days. Section 5 gives the main results of this study, that is, the diagnostics of the emissions. In section 6 , we discuss the impacts of possible systematic model errors on the diagnostics. Section 7 contains a summary and a conclusion.

\section{Airborne Measurements}

\subsection{Flight Routes}

[12] The airborne measurements were made during the field campaign of the ESQUIF project [Menut et al., 2000] during the summers of 1998 and 1999. Up to five airplanes were used during IOPs. These IOPs lasted $1-3$ days and were selected according to weather and regional ozone forecasts [see also Vautard et al., 2001]. Several flight routes were designed prior to the experiment, according to the objectives of the project. In this study, we only use the measurements gathered from the "regional flights," carried out by the two Piper AZTEC aircraft operated by Mété France and the Laboratoire des Sciences du Climat et de l'Enivironnement (LSCE), denoted hereinafter as AZTECCAM and AZTEC-LSCE, respectively, and by one motor glider, Eco DIMONA (hereinafter called DIMONA), operated by the Swiss MetAir company. 


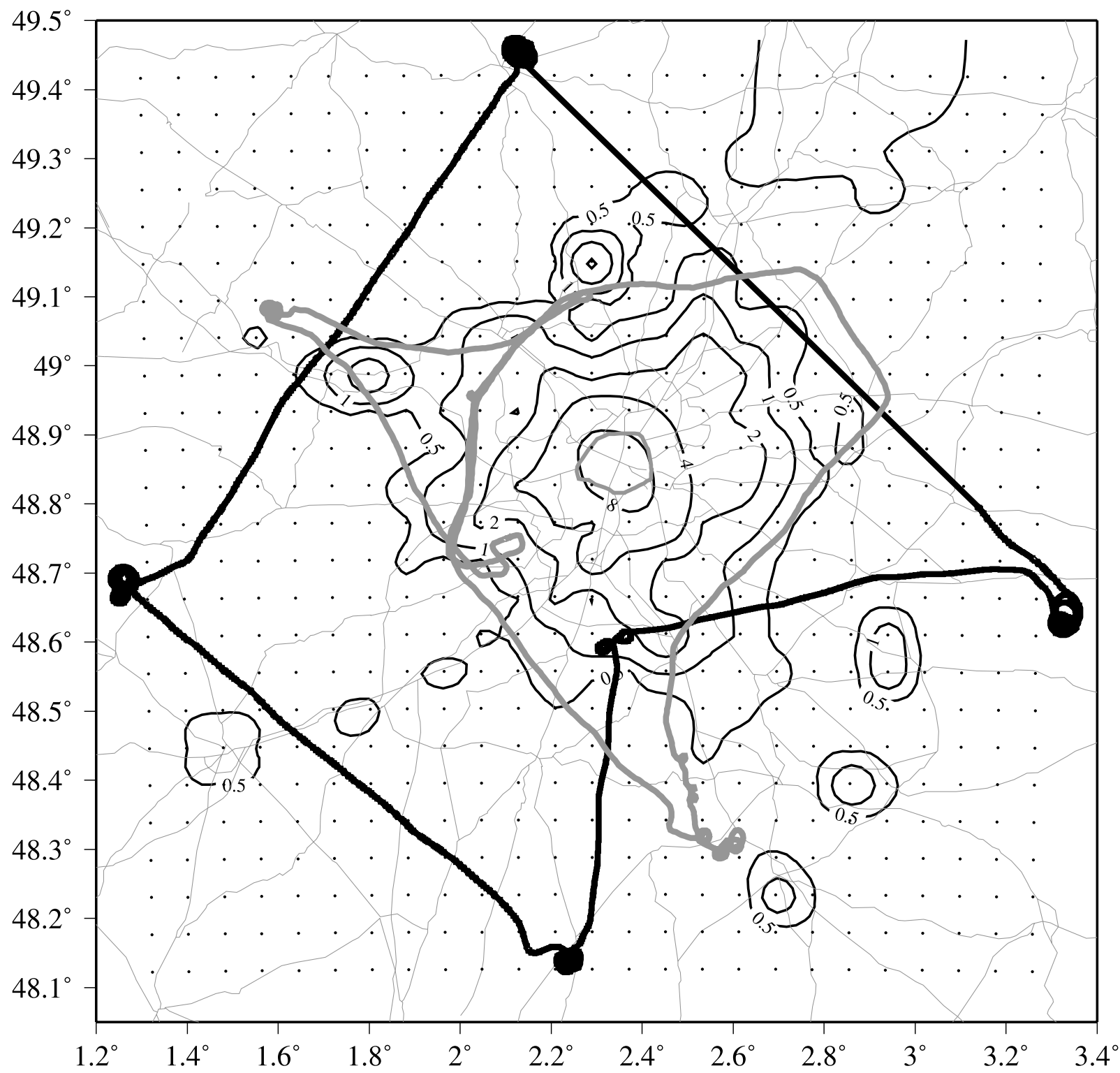

Figure 1. Contours of the NO emissions (units are $10^{12}$ molecules $\mathrm{cm}^{-2} \mathrm{~s}^{-1}$ ) for the month of July (all activity sectors included) at $0700 \mathrm{UT}$ at traffic rush hour with two flight patterns during the ESQUIF period. Paris is in the center of the map. The gray route was used by DIMONA and the black by one of the AZTEC aircraft, with four vertical profiles performed. The model grid is represented (dots) together with main roads and the contour of the city of Paris. The size of the domain is $\sim 160 \times 160 \mathrm{~km}$.

[13] Since the aim of the study is emission diagnostics, the flight routes are designed in such a way that the Paris plume cannot be missed. They consist, in general, of a more or less circular pattern, with possible extra time spent in the plume. Some measurements along the vertical direction were also carried out in order to obtain vertical profiles of concentrations. These profiles, which are taken upwind, downwind, or crosswind, help document the structure of the boundary layer and the background and plume concentrations. Figure 1 gives examples of DIMONA and AZTEC flight patterns.

[14] Table 1 summarizes the flights that have been used for this study. These were not the only flights performed during ESQUIF. During most of the IOP days, light winds, high temperatures $\left(>25^{\circ} \mathrm{C}\right)$, and clear skies were observed.
Afternoon flights were used for this study in order to have measurements taken from within a well-mixed boundary layer.

\subsection{Measured Species and Methods}

2.2.1. DIMONA Measurement Methods and Accuracy [15] The three aircraft have different sensors for measuring chemical compounds. Several meteorological parameters were measured but are not used in this study. For the DIMONA aircraft a detailed description of the meteorological and chemical instrumentation can be found in Neininger et al. [2001]. The instruments were located in two underwing pods. The inlet lines of the instruments in the pods were very short $(<0.5 \mathrm{~m})$ and could not be contaminated by 
Table 1. Summary of Flights Used

\begin{tabular}{lcc}
\hline Date & Flight Time, UT & Aircraft \\
\hline 16 June 1999 & $1300-1400$ & AZTEC-LSCE \\
25 June 1999 & $1221-1621$ & DIMONA \\
25 June 1999 & $1200-1400$ & AZTEC-CAM \\
25 June 1999 & $1300-1430$ & AZTEC-LSCE \\
2 July 1999 & $1300-1500$ & AZTEC-LSCE \\
2 July 1999 & $1230-1430$ & AZTEC-CAM \\
2 July 1999 & $1222-1634$ & DIMONA \\
16 July 1999 & $1135-1536$ & DIMONA \\
17 July 1999 & $1230-1500$ & AZTEC-CAM \\
17 July 1999 & $1500-1600$ & AZTEC-LSCE \\
17 July 1999 & $1416-1824$ & DIMONA \\
18July 1999 & $1500-1600$ & AZTEC-LSCE \\
18 July 1999 & $1216-1615$ & DIMONA \\
30 July 1999 & $1600-1730$ & AZTEC-LSCE \\
\hline
\end{tabular}

exhaust gases (proved during each flight, when, for example, $\mathrm{NO}_{x}$ and VOCs above the boundary layer dropped toward the detection limits).

[16] $\mathrm{O}_{3}$ was measured by a miniaturized UV photometer. It was calibrated before and after the campaign against a UV absorption instrument (Monitorlabs) having a calibration traceable to the U.S. National Institute of Standards and Technology (NIST).

[17] $\mathrm{NO}_{2}, \mathrm{NO}_{x}, \mathrm{NO}_{y}, \mathrm{NO}_{x}+$ peroxyacetyl nitrate (PAN), and $\mathrm{O}_{x}$ were measured by the luminol chemiluminescence technique and by suitable converters with an instrument of MetAir's design: " $\mathrm{NO}_{x} \mathrm{TO}_{y}$ " $\left(\mathrm{CrO}_{3}\right.$ for $\mathrm{NO}$ to $\mathrm{NO}_{2}$, Mo at $350^{\circ} \mathrm{C}$ directly at the intake for $\mathrm{NO}_{y}$ to $\mathrm{NO}$, an oven at $125^{\circ} \mathrm{C}$ after $\mathrm{CrO}_{3}$ to get $\mathrm{NO}_{x}+\mathrm{PAN}$, and injection of $\mathrm{NO}$ for titrating $\mathrm{O}_{3}$ to $\mathrm{NO}_{2}$ ). The accuracy of the DIMONA $\mathrm{NO}_{y}$ data is estimated to $0.5 \mathrm{ppbv}$ or $10 \%$ of the measured concentration.

[18] The nonmethane hydrocarbons were measured with an on-board gas chromatography system, "Airmotec HC1010" [Konrad and Volz-Thomas, 2000]. A measuring cycle consisted of 9 min for air sampling, 1 min to transfer the sample to the capillary column, and $10 \mathrm{~min}$ for chromatography. A new sample can be drawn while analyzing the previous sample. This leads to quasi-continuous measurements with $\sim 10 \mathrm{~min}$ averaging time. The instrument measures hydrocarbons from $\mathrm{C} 4$ to $\mathrm{C} 10$. The accuracy of the measurements lies well below the $20 \%$ limit.

\subsubsection{AZTEC Measurement Methods and Accuracy}

[19] The sampling inlet set up in the AZTEC-LSCE consisted of a 0.25 inch stainless steel tubing through which ambient air was drawn up by the vacuum previously created in the stainless canister. The tube inlet was located $25 \mathrm{~cm}$ away from the aircraft window and sampled the air from a reverse flow. After flushing the line for $1 \mathrm{~min}$ with a small pump at a $0.51 \mathrm{~min}^{-1}$ flow rate, the sampled air was stored in the 0.81 inox canister. The duration of the filling-up was $<1 \mathrm{~min}$. This sampling technique has been previously used and described by Bonsang and Lambert [1985]. Owing to the aircraft equipment, only nine samples per flight could be taken.

[20] Aboard the AZTEC-CAM aircraft the sampling procedure was different. The inlet antenna was mounted above the cabin out of the boundary surface of the air stream. The $2 \mathrm{~m}$ tube line was made of decabon and the canister was made of glass. The canister was filled after flushing the line and the glass canister itself for $5 \mathrm{~min}$. Then the air was compressed in 31 glass flasks. Compression was controlled by a regulator and was achieved up to 1.5 bars at $3 \mathrm{~km}$ height. The sampling time was $\sim 5 \mathrm{~min}$. The capability to use such glass flasks has been assessed by Touaty [1999] for $\mathrm{CO}$ and nonmethane hydrocarbon chromatography analysis. In particular, Touaty shows that no contamination occurs when the samples are analyzed within 2 months after the sampling. In this aircraft, 13 samples were taken.

[21] All samples were analyzed in the laboratory within 2 months after the data collection. For the analysis of NMVOCs, after a double preconcentration procedure the gas is extracted through a chromatograph and is analyzed with a flame ionization detector according to a technique described by Bonsang and Lambert [1985] and by Kanakidou et al. [1989]. The detection limit was found to be of the order of $5 \mathrm{pptv}$, and the accuracy of the analytical technique was previously estimated by Boissard [1992] to 6\% for NMVOCs lower than C5. For higher NMVOCs, accuracy is believed to be poorer.

[22] Analysis of CO flask content was performed in the laboratory by a chromatography technique described in detail by Gros [1998]. The accuracy of the measurement was $\sim 4 \%$. Other substances were also measured aboard the two AZTEC aircrafts but are not used in this study.

\subsection{Measurements Used in This Study}

[23] Our approach here is to make the emission diagnostics as exhaustive as possible, so even species measured with a certain degree of uncertainty are considered. We use AZTEC flights for measurements of $\mathrm{CO}$ and $\mathrm{C} 2-\mathrm{C} 6$ hydrocarbons, even though the quality of the $\mathrm{C} 6$ measurements is questionable. We use DIMONA flights for measurements of $\mathrm{NO}_{y}, \mathrm{O}_{3}, \mathrm{NO}_{2}$, and $\mathrm{C} 4-\mathrm{C} 10$ hydrocarbons, provided that the total number of available measurements exceeds 10 in total. Some species were excluded because either their $\mathrm{OH}$ chemistry was hardly known or because the inventory emission speciation was not given. The resulting list of selected compounds can be found in Table 2 .

[24] For DIMONA flights a total of 27 hydrocarbons are considered. In three cases, two hydrocarbons are grouped due to coelution problems. By summing up the emissions of the inventory, which will be presented in section 3.1 below, over a $150 \times 150 \mathrm{~km}$ area around Paris (the model domain, see Figure 1), these hydrocarbons represent $44 \%$ of the total emitted mass for a typical July day. When excluding species believed to have low reliability, one ends up with a fraction of $33 \%$ of the total mass. For AZTEC flights the equivalent fractions are $26 \%$ and $23 \%$, respectively. If we now consider the ensemble of measured (for all aircraft) species, the mass fraction rises up to $53 \%$, and the reliable fraction is $51 \%$. Hence the measurements taken cover about half of the total NMVOC emitted mass. Other nonmeasured species that account significantly for total mass fraction are other alkanes $(10 \%)$, alkenes $(5 \%)$, aromatics $(4 \%)$, oxygenated compounds (22\%), and halogenated VOCs and unspecified $(6 \%)$.

[25] In terms of molecular reactivity the propene-equivalent fraction of measured reactivity is $26 \%$ for DIMONA, $20 \%$ for AZTEC, and $41 \%$ in total. The latter equivalent fraction for reliable measurements is $39 \%$. The contribution 
Table 2. List of Species and Type of Aircraft Used, Together With NMVOC Reactivity and References for Reactivity ${ }^{\mathrm{a}}$

\begin{tabular}{|c|c|c|c|c|c|}
\hline Species & DIMONA & AZTEC & Remarks/Accuracy & $\begin{array}{l}K \mathrm{OH} \times 10^{12} \\
\mathrm{~cm}^{3} \text { molecule } \\
\end{array}$ & Reference \\
\hline Ozone & $\mathrm{X}$ & & stable within 2 ppbv for 10 years & & \\
\hline $\mathrm{NO}_{2}$ & $\mathrm{X}$ & & $\begin{array}{l}0.5 \text { ppbv } \pm 10 \% \text { of concentration } \\
\quad \text { (interference of } \mathrm{O}_{3} \text { and PAN corrected) }\end{array}$ & & \\
\hline $\mathrm{NO}_{y}$ & $\mathrm{X}$ & & $\begin{array}{l}0.5 \mathrm{ppbv} \pm 10 \% \text { of concentration } \\
\quad\left(\text { no interference with } \mathrm{O}_{3} \text { ) }\right.\end{array}$ & & \\
\hline $\mathrm{CO}$ & & $\mathrm{X}$ & $1.5 \mathrm{ppbv}$ & & \\
\hline NMVOCs & $\mathrm{X}$ & $\mathrm{X}$ & $\begin{array}{l}10 / 50 \text { pptv or } 20 \% \text { for DIMONA, } \\
5 \text { pptv and } \sim 6 \% \text { for AZTEC }\end{array}$ & & \\
\hline Ethane & & $\mathrm{X}$ & & 0.254 & A97a \\
\hline Ethene & & $\mathrm{X}$ & & 8.52 & A97a \\
\hline Ethine & & $\mathrm{X}$ & & 0.83 & A97b \\
\hline Propane & & $\mathrm{X}$ & & 1.12 & A97a \\
\hline Propene & & $\mathrm{X}$ & & 26.3 & A97a \\
\hline Isobutane & $\mathrm{X}$ & $\mathrm{X}$ & uncertain for DIMONA & 2.19 & A97a \\
\hline$N$-butane & $\mathrm{X}$ & $\mathrm{X}$ & $\begin{array}{l}\text { coeluting with 1-butene and other unknown } \\
\text { C4-hydrocarbons for DIMONA }\end{array}$ & 2.44 & A97a \\
\hline Isopentane & $\mathrm{X}$ & $\mathrm{X}$ & & 3.70 & A97a \\
\hline$N$-pentane & $\mathrm{X}$ & $\mathrm{X}$ & & 4.00 & A97a \\
\hline 2-methylpentane & $\mathrm{X}$ & & uncertain, coeluting with methylbutylether & 5.3 & A97a \\
\hline 3-methylpentane & $\mathrm{X}$ & & uncertain, coeluting with unknown & 5.4 & A97a \\
\hline$N$-hexane & $\mathrm{X}$ & $\mathrm{X}$ & uncertain for AZTEC & 5.45 & A97a \\
\hline 2.4-dimethylpentane & $\mathrm{X}$ & & coeluting with methylcyclopentane & 5.0 & A97a \\
\hline Benzene & $\mathrm{X}$ & $\mathrm{X}$ & $\begin{array}{l}\text { possibly coeluting with cyclohexane, } \\
\text { uncertain for AZTEC }\end{array}$ & 1.50 & $\mathrm{MCM}$ \\
\hline \multirow{2}{*}{$\begin{array}{l}\text { 2-methylhexane }+ \\
\text { 2.3-dimmethylpentane }\end{array}$} & $\mathrm{X}$ & & the two species coeluting & 6.78 & MCM \\
\hline & & & & 5.0 & A97a \\
\hline 3-methylhexane & $\mathrm{X}$ & & & 7.16 & MCM \\
\hline$N$-heptane & $\mathrm{X}$ & & & 7.02 & A97a \\
\hline Toluene & $\mathrm{X}$ & & possibly coeluting with 2-methylheptane & 5.96 & MCM \\
\hline$N$-octane & $\mathrm{X}$ & & & 8.71 & A97a \\
\hline Ethylbenzene & $\mathrm{X}$ & & & 7.10 & $\mathrm{MCM}$ \\
\hline$M$ - and $p$-xylene & $\mathrm{X}$ & & the two species coeluting & 23.6 and 14.3 & $\mathrm{MCM}$ and MCM \\
\hline$O$-xylene & $\mathrm{X}$ & & & 13.7 & MCM \\
\hline$N$-nonane & $\mathrm{X}$ & & & 10.0 & A97a \\
\hline$N$-propylbenzene & $\mathrm{X}$ & & possibly coeluting with benzaldehyde and camphene & 6.0 & MCM \\
\hline$M$ - and $p$-ethyltoluene & $\mathrm{X}$ & & the two species coeluting & 19.2 and 12.1 & $\mathrm{MCM}$ and $\mathrm{MCM}$ \\
\hline$O$-ethyltoluene & $\mathrm{X}$ & & possibly coeluting with $b$-pinene & 12.3 & MCM \\
\hline$N$-decane & $\mathrm{X}$ & & & 11.2 & A97a \\
\hline 1,2,4-trimethylbenzene & $\mathrm{X}$ & & & 32.5 & MCM \\
\hline 1.2.3.-trimethylbenzene & $\mathrm{X}$ & & possibly coeluting with $p$-cymene & 32.7 & $\mathrm{MCM}$ \\
\hline
\end{tabular}

${ }^{a}$ NMVOC reactivity is shown in column 5 and references for reactivity are shown in column 6 . This list does not contain other species which were measured aboard the aircraft. Some qualitative/quantitative remarks are added. Three body reactions have been calculated by assuming a density of $2.5 \times$ $10^{19}$ molecules $\mathrm{cm}^{-3}$. A97a is Atkinson [1997]; A97b is Atkinson et al. [1997]; MCM denotes rate constants given by the University of Leeds Master Chemical Mechanism (http://www.chem.leeds.ac.uk/Atmospheric/MCM/mcmproj.html) and described by Jenkin et al. [1997].

of nonmeasured species is $9 \%$ for other alkanes, $22 \%$ for other alkenes, $10 \%$ for other aromatics, $15 \%$ for oxygenated compounds, and 3\% for unspeciated compounds. The important numbers to remember are that about half of the total mass and $40 \%$ of the reactivity are diagnosed by using the airborne measurements.

\section{The Anthropic Emission Inventory and the Chemistry Transport Model}

\subsection{The Anthropic Emission Inventory}

[26] The anthropic emissions are obtained with the emission module of the Système Informatique de Modélisation de la Pollution Atmosphérique à l'échelle Régionale (SIMPAR) modeling system [ARIA Technologies, 2000]. SIMPAR is a tool for analyzing and understanding pollution episodes and is used to carry out hypothesis tests in order to validate initiatives for reducing emissions. This system, installed for AIRPARIF by the company ARIA Technologies between 1997 and 1999, is made up of a series of software applications (MINERVE, HERMES, AIRQUAL, UAM-V, etc.) developed by research teams in France (Electricité de France, Institut Français du Pétrole, Laboratoire Interuniversitaire des Systèmes Atmosphériques) and in the United States (Systems Applications International). The inventory is made of estimates of carbon monoxide (CO), sulphur dioxide $\left(\mathrm{SO}_{2}\right)$, nitrogen oxides $\left(\mathrm{NO}_{x}\right)$, and NMVOCs at the temporal and spatial resolutions of $1 \mathrm{~h}$ and $3 \mathrm{~km}$, respectively. The inventory is compiled for 3 days in July 1998 (weekday, Sunday, Saturday) over a $150 \times$ $150 \mathrm{~km}$ grid. It takes into account emissions from large point sources (sources whose capacity exceeds $20 \mathrm{MW}$ or whose annual emissions of $\mathrm{SO}_{2}$ or $\mathrm{NO}_{x}, \mathrm{NMVOCs,} \mathrm{HCl}$, or PS exceed 150 t) and line sources (major streets and highways) as well as area sources (sources which are not included in the previous categories, such as local heating or extra-urban road traffic). Emission values are classified using the source sectors (by the SNAP code, selected nomenclature for air pollution developed in the frame of CORINE to relate emissions of air pollutants to relevant 


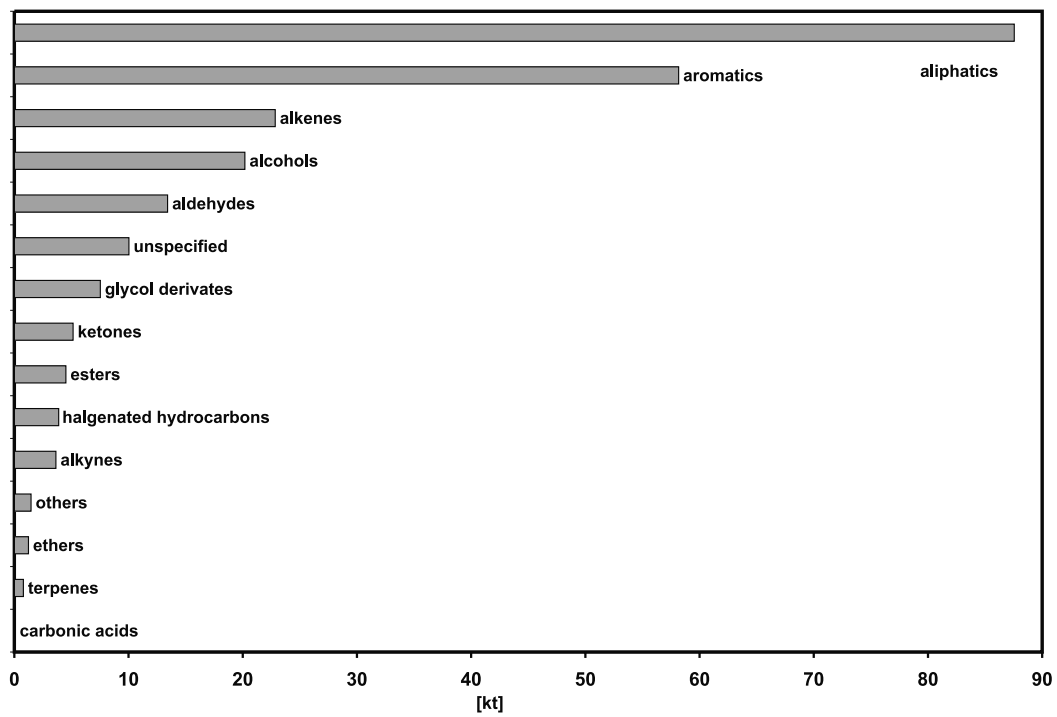

Figure 2. Integrated VOC speciation in terms of total mass for Paris aggregated to chemical substance classes.

sectors, subsectors, and activities) from the Coordination of Information on Air Emissions European methodology.

\subsubsection{Point Sources}

[27] Annual emissions from point sources are based on 1998 data collected by the Direction Régionale de l'Industrie, de la Recherche et de l'Environnement institute and come directly from the industry. Within the Paris area, 203 point sources are taken into account. These sources include production processes, extraction and distribution of fossil fuels, solvent use, other mobile sources and machinery (including air traffic), and waste treatment and disposal.

\subsubsection{Area Sources}

[28] Annual emissions for area sources are prepared by the national emission inventory institution called the Centre Interprofessionnel Technique d'Etudes de la Pollution Atmosphérique [Centre Interprofessionnel Technique d'Etudes de la Pollution Atmosphérique, 1997]. These emissions are actually valid for 1994 and are distributed on small administrative areas, then refined using local land use characteristics.

\subsubsection{Line Sources}

[29] Emissions from road traffic are calculated using vehicle fleet, traffic activity data describing an average weekday for each main segment of the road network of the Paris area, and emission factors. Information on national vehicle fleet and technology is obtained for the main road types (urban roads, rural roads, and highways) from the Institut National de Recherche sur les Transports et leur Sécurité according to Bourdeau [1998]. In addition, information from some reports of the Paris council and from the work of Sallès et al. [1996] were used in addition to the national information in order to obtain regional data on an hourly basis. Emission factors are derived from the European Computer Programme to Calculate Emissions from Road Transport (COPERT 3) methodology [Ntziachristos and Samaras, 2000].

\subsubsection{Time Distributions}

[30] The split of annual emissions from point and area sources into an hourly distribution is achieved using monthly, weekly, and diurnal profiles for each of the first two levels of the emission sectors (SNAP code). These factors are derived both from industries and from a calculation made under the Generation of Emission Data (GENEMIS) [Friedrich and Reis, 2003] project. This methodology is applied to all but line sources emissions since for these latter the diurnal profile is directly calculated from the traffic model.

\subsubsection{NO NO $_{x}$ and NMVOC Speciation}

[31] The $\mathrm{NO}_{x}$ speciation consists of $10 \%$ emitted $\mathrm{NO}_{2}$ and $90 \%$ emitted $\mathrm{NO}$ (in $\mathrm{NO}_{2}$-equivalent mass units). The NMVOC speciation is carried out by a disaggregation for every emission sector or SNAP code from available literature information and partly from expert interviews. The emissions from solvent use are distributed into single components in a study from the work of Theloke et al. [2000]. The method is briefly described by Theloke et al. [2001]. A satisfactory disaggregation of solvent emissions to single components was reached by using additional information about the composition of white spirits [Rudd and Marlowe, 1998]. Disaggregation of traffic NMVOC emissions is based on a study from the work of Hassel et al. [2000] and of Schmitz et al. [2000]. The measurements were carried out according to the US-test 75 and the highway cycle. The results are aggregated to the corresponding SNAP codes by J. Theloke and A. Obermeier (personal communication, 2001). The composition of the other source groups was taken from many different information sources. More detailed information about the method, with detailed information about the literature sources, is in preparation (J. Theloke et al., manuscript in preparation, 2003). Figure 2 shows the resulting total NMVOC mass distribution. Most of the mass is due to the alkanes and aromatics, but a significant mass fraction is due to oxygenated compounds. However, we will not be able to evaluate the emissions from these latter species since they are not measured in our study. 3.1.6. Resulting Inventory

[32] The analysis of the resulting emission inventory shows that road traffic is mainly responsible for nitrogen 
oxide emissions (53\% of total $\mathrm{NO}_{x}$ emissions), while two types of sources, namely the use of solvents (36\%) and traffic $(35 \%)$, are responsible for the largest part of NMVOC emissions. Concerning $\mathrm{CO}$, the most important amount of emissions is produced by combustion, followed by road traffic.

[33] The spatial distribution of NO emissions for a weekday of July at 0700 UT (Figure 1) clearly illustrates the high emission levels over Paris and inner suburban areas. These levels are mainly due to the large concentration of road traffic in the urban area, while the rural areas $\sim 50 \mathrm{~km}$ away from the center exhibit very light emissions, except those from a few point sources.

\subsection{The Chemistry Transport Model}

[34] The model used throughout this study is the CHIMERE model [Schmidt et al., 2001] (see also the web site http://euler.lmd.polytechnique.fr/chimere) developed at the Institut Pierre-Simon Laplace, Paris, France. It is a simplified three-dimensional chemistry transport model which was designed in the first place for ozone forecasting in the Paris area [Vautard et al., 2001]. We use here a multiscale version of the model, with a regional version $(150 \times 150 \mathrm{~km}$, centered around Paris with a $6 \times 6 \mathrm{~km}$ resolution) nested into a large-scale version covering western Europe. For the sake of conciseness, we chose to put the emphasis on the setup of the experiments and refer the reader to the article of Schmidt et al. [2001] and the abovementioned web site for the model description and further details about the model formulation.

\subsubsection{Nested Model Setup}

[35] In order to describe boundary concentrations of key species such as ozone and precursors, we first run the largescale version of CHIMERE. This version has a $0.5^{\circ}$ horizontal resolution and covers most of western Europe. In the vertical direction a low resolution is taken, with six hybrid $\sigma$-p levels from the surface to the $700 \mathrm{hPa}$ surface, so it encompasses the boundary layer and a few hundred meters above, except sometimes over mountainous areas. As compared with the Schmidt et al. [2001] model, one layer has been added by splitting their second layer into two sublayers in order to better resolve mixing near the surface. The boundary conditions of this large-scale model are taken from the climatologies of the Model for Ozone and Related Chemical Tracers (MOZART) [Hauglustaine et al., 1998] and vary only with the calendar month. Meteorological forcing is given by the 6 hour European Centre for Medium-Range Weather Forecasts (ECMWF) short-term forecasts, which are available at a 3 hourly sampling rate. Emissions at European scale are taken from the annual European Monitoring and Evaluation Programme (web site http://www.emep.int) totals for 1999 on the $50 \times 50 \mathrm{~km}$ grid and are distributed in time from GENEMIS typical profiles.

[36] A long simulation of this large-scale model is performed, starting on 10 June 1999 and ending on 31 July 1999 , in order to avoid spin-up problems (the first day studied here is 16 June 1999). Once this simulation is performed, the concentrations obtained at the limits of the regional model are used as boundary conditions, with no feedback from the small-scale model to the large-scale one (one-way nesting). However, for the sake of memory management, only a few key species are passed to the regional model. These are ozone, $\mathrm{CO}, \mathrm{NO}_{2}, \mathrm{PAN}, \mathrm{HNO}_{3}$, and the model NMVOCs.

[37] The small-scale model extent $(150 \times 150 \mathrm{~km})$ is shown in Figure 1. It has the same vertical resolution (six layers) as the large-scale model but a horizontal resolution of $6 \mathrm{~km}$. In order to force the model the ECMWF meteorological data are linearly interpolated onto the model grid. We therefore make the assumption that large-scale meteorological parameters are representative of the flow at the scale of the Paris region. This assumption is justified by two arguments. The a priori argument is that, as stated in the introduction, owing to its geographical location, the Paris area boundary layer should not undergo strong mesoscale meteorological phenomena. The a posteriori argument is that the regional model fed by these low-resolution data produces realistic daily ozone forecasts in this area [Vautard et al., 2001], although it has been noted to be difficult to accurately reproduce plume locations under very stagnant conditions. However, plume intensity is generally well reproduced.

\subsubsection{NMVOC Simulations}

[38] The chemical mechanism of CHIMERE, described by Lattuati [1997], is an extended and updated version of the Hov et al. [1985] mechanism. It explicitely calculates photooxidants, reactive nitrogen, carbon monoxide, and all species resulting from the degradation of 11 representative anthropic NMVOCs as well as $\alpha$-pinene representing the class of all terpenes. These NMVOCs are ethane, $n$-butane, ethene, propene, isoprene, $o$-xylene, formaldehyde, acetaldehyde, methyl-ethyl-ketone, methanol, and ethanol. As in many CTMs, the inventory NMVOC emissions are lumped into these model NMVOCs using the procedure proposed by Middleton et al. [1990], which accounts for the difference in reactivity between real NMVOCs and model NMVOCs. Here this method is applied after estimating reactivity relative to $\mathrm{OH}$ of the more than 300 NMVOCs described in the inventory, using information from rateconstant compilations [Atkinson, 1997; Atkinson et al., 1997], from the NIST database (http://www.kinetics.nist. gov), from the University of Leeds Master Chemical Mechanism [Jenkin et al., 1997], and from structure-reactivity relationships [Kwok and Atkinson, 1995].

[39] However, this methodology does not allow the simulation of individual NMVOCs as they are measured in the atmosphere by gas chromatography, and therefore it makes the model/observation comparisons difficult. In order to solve this problem, one possibility is to simulate all the measured species and to include them in the chemical mechanism after removing them from the lumping process. However, this would mean a drastic increase in the number of chemical reactions. Not only would we have to include NMVOC oxidation by $\mathrm{OH}$ but also all the degradation of subsequent products, which is not always known. We choose instead a two-way procedure, where (1) a simulation is performed with the original chemical mechanism and full lumping in order to calculate $\mathrm{OH}$, but also $\mathrm{NO}_{y}$ and ozone, and (2) the resulting $\mathrm{OH}$ concentration is used in a second, offline simulation, where only reactions between each individual NMVOC and $\mathrm{OH}$ is considered.

[40] In the second stage we make the assumption that the only major chemical degradation of the NMVOCs is 
achieved with $\mathrm{OH}$, and we omit reactions with ozone or the nitrate radical. While this simplification is relevant for daytime reaction with $\mathrm{NO}_{3}$, the $\mathrm{O}_{3}$ reaction with alkenes can lead to model overestimations for these hydrocarbons.

[41] The NMVOCs considered here for comparison with measurements are also listed in Table 2, together with the $\mathrm{OH}$ reactivity at $298 \mathrm{~K}$. In the following, model/observation comparisons will be carried out by using the second simulation for NMVOCs and the first simulation for all other species.

\section{Spatial Distribution of Simulated Versus Observed Mixing Ratios}

[42] The aim of this section is to present qualitative comparisons between simulated mixing ratios and airborne measurements. It is designed to demonstrate that model simulations show reasonable agreement with observations.

\subsection{Photooxidants}

[43] Figure 3 shows the contours of the $\mathrm{O}_{x}$ mixing ratio maps simulated by the model, superimposed with the mixing ratios measured aboard the DIMONA aircraft, for the five afternoon flights used in this study. Since it is impossible to represent a unique map for the different times and altitudes of the flight, we display the simulated map in model layer 3 (roughly 280-600 m above ground), where most measurements were taken, and for the central time of the flight. Note that measurements are averaged every $10 \mathrm{~min}$, so their geographical location is not exact but is the "average" aircraft location during the $10 \mathrm{~min}$.

[44] At first sight the model is reproducing the $\mathrm{O}_{x}$ mixing ratios in a qualitatively correct manner. The simulated amplitudes of the $\mathrm{O}_{x}$ plume (the difference between downwind and upwind sides) are in the same range as the observed ones, although slightly too weak on 25 June. The "background level," provided by the large-scale model simulation, is also fairly realistic, except on 25 June where it is too large by $\sim 10-15$ ppbv in the southeast corner of the model domain. Note also a slight underestimation (5-10 ppbv) on 16 July.

[45] The plumes' direction and extent are not always captured: on 16 July the simulated plume has a larger extension than the observed plume, but only one observation is apparently taken in the plume core. On 17 July the extent of the simulated plume seems too short. On 18 July the plume is observed on the northeast side of Paris while it is simulated on the northwest side. A more complete investigation of the simulated values and of the meteorological forcing shows that, actually, wind direction is switching from east to southwest during that latter day, introducing a strong sensitivity of plume location to small errors in the wind field. One possible explanation for the simulation error is, therefore, wrong timing in the wind direction change.

[46] The fact that photooxidants are reasonably well simulated gives a relative confidence in the ability of the model to simulate the overall chain of photooxidation and, in particular, $\mathrm{OH}$ and the rates of NMVOC oxidations.

\subsection{Reactive Nitrogen}

[47] Figure 4 shows, in the same format as Figure 3, the comparisons between observed and simulated $\mathrm{NO}_{y}$ mixing ratios. Observed and simulated concentrations vary from 0 to 30 ppbv. Background values are always overestimated, except on 16 July. This overestimation can reach a factor of 2 (on 25 June and 18 July). Since the simulated background concentrations mostly come from the transport of concentrations simulated by the large-scale model into the regional model domain, we therefore suspect a bias toward too high $\mathrm{NO}_{y}$ due to the large-scale model itself.

[48] On the contrary, plume amplitudes are reasonably well simulated, with the same discrepancies in the directions as already mentioned for the $\mathrm{O}_{x}$ plumes. However, we note a significant overestimation (by a factor $\sim 1.5$ ) of the $\mathrm{NO}_{y}$ plume amplitude on 17 July and a smaller overestimation on 18 July. This could be due to several problems. First, these days are weekend days, and the space/time variations of emissions are uncertain. The error could also come from an underestimated boundary layer height. On 17 July the DIMONA aircraft recorded measurements along the vertical direction in the core of the city plume. Figure 5 shows two vertical profiles of $\mathrm{NO}_{y}$ mixing ratios taken in the plume on 17 July and the corresponding simulated values. The simulated vertical profile is not correct, with too high values at low altitudes and too low values at high altitudes. This is due to a severe underestimation of the boundary layer height (BLH) in the model $(\sim 1200 \mathrm{~m}$, while the observed one is $\sim 1900 \mathrm{~m}$; see section 6.1). Unfortunately, we do not have plume vertical profiles for other IOP days (except for 2 July 1999, where differences are much less marked) to make these comparisons systematic. Using lidar measurements of the BLH, we show in section 6.1 that the model BLH is underestimated on average but not in a systematic manner, so that the plume amplitudes should, if the emissions are correct, also be overestimated.

\subsection{Other Primary Species}

[49] For carbon monoxide (not shown), there are larger differences between observed and simulated values both in the plume and in background values, simulated $\mathrm{CO}$ concentrations being too large. This could hint at an overestimation of the $\mathrm{CO}$ emissions, which will be discussed in section 5.2. However, it has to be noted that there are fewer measurements due to the technique used (bottle sampling), and the plume may therefore be undersampled.

[50] For total measured NMVOCs (not shown) we performed the same kind of qualitative comparisons, but now background values cannot be compared since in the model experiments they are set to zero. The simulated mixing ratios and the observed mixing ratios are in a similar range within plumes. Again, plume direction mismatches are observed at the same locations and times as for $\mathrm{NO}_{y}$. Overestimation of NMVOC plume amplitudes are also observed on 17 and 18 July, as for $\mathrm{NO}_{y}$, resulting, probably, from the underestimation of the BLH or uncertainties in the inventory for weekend days.

[51] To conclude this section, we have shown that the simulation of the most important species generally reproduces the range of the observed values quite well despite errors in plume locations and also in background values. Only simulated CO concentrations display larger differences relative to observed values, which indicates a possible bias in $\mathrm{CO}$ emissions. However, at least for 17 July, the vertical profile of $\mathrm{NO}_{y}$ is incorrect due to a severe under- 

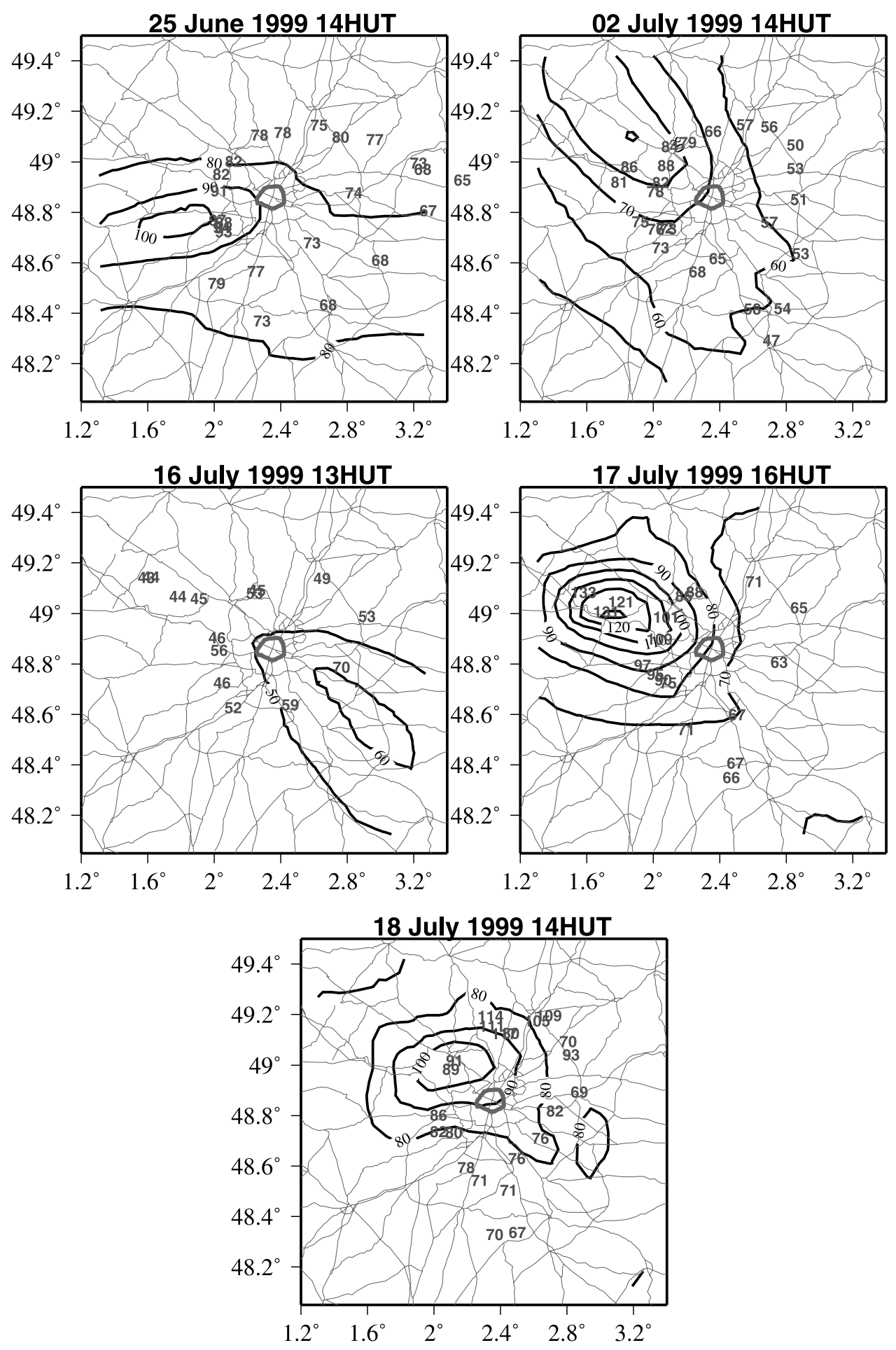

Figure 3. Simulated (contours) $\mathrm{O}_{x}$ mixing ratios $\left(\mathrm{O}_{x}=\mathrm{O}_{3}+\mathrm{NO}_{2}\right)$ superimposed with measurements aboard DIMONA for all five afternoon flights during ESQUIF. Values are in ppbv. Contours are displayed for the central time of the flight and model level 3. The domain is that of the simulation regional model with an extent of $150 \times 150 \mathrm{~km}$. The contour of the city of Paris is displayed by a thick shaded line. 

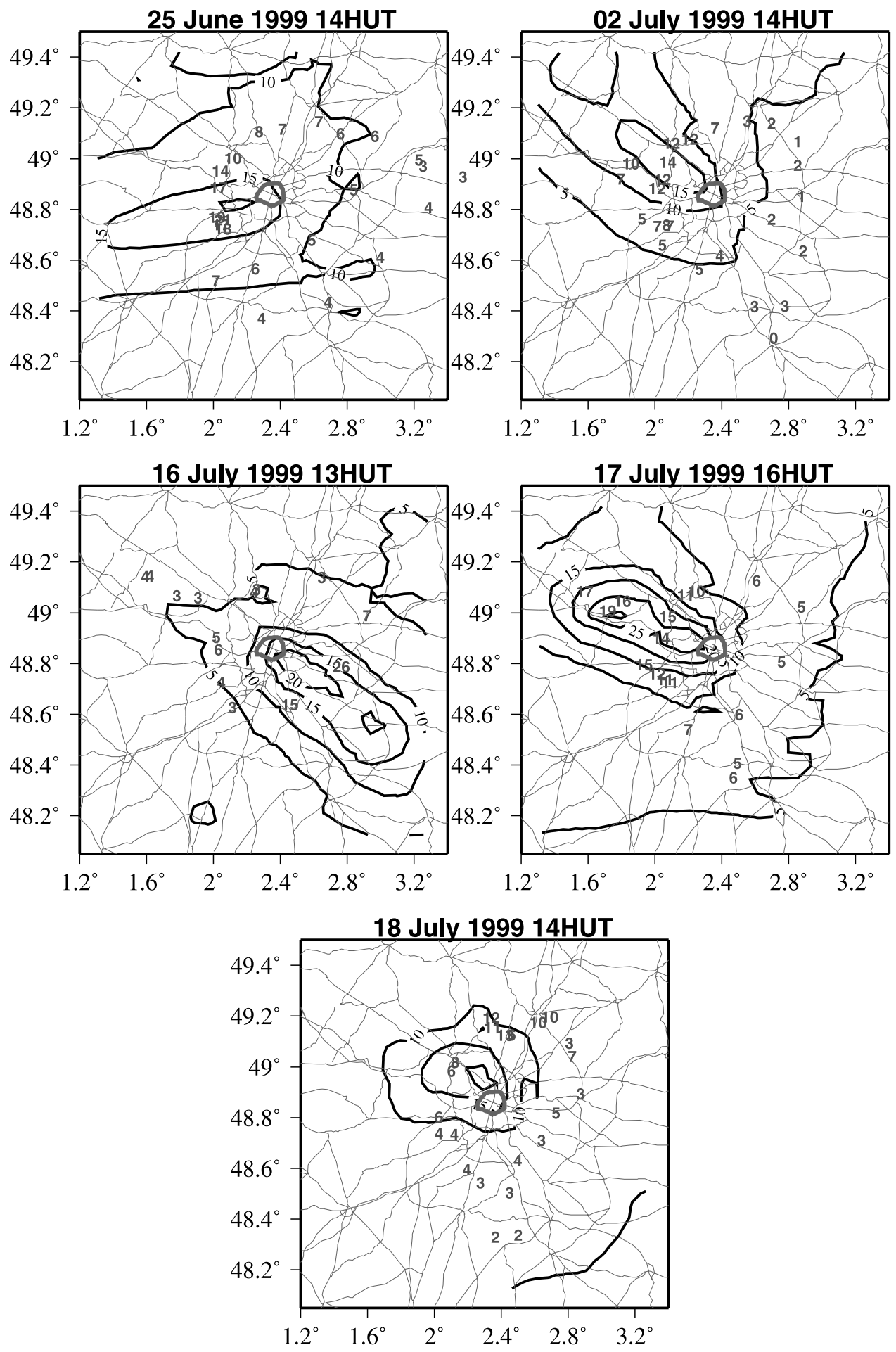

Figure 4. Same as Figure 3, but for $\mathrm{NO}_{y}$ mixing ratios.

estimation of the boundary layer height. In section 5 , the differences between simulations and observations are examined in a quantitative manner.

\section{Emissions Diagnostics}

\subsection{Methodology}

[52] In this section, an attempt is made to quantify the simulated versus observed concentrations and to draw conclusions about possible errors in the regional emission inventory. The interpretation of the differences between simulations and observations in terms of differences in emissions may be obscured by several factors: (1) background concentrations given to the regional model can be erroneous; (2) measurement data locations must be the receptors of the regional emissions; (3) transport and mixing can be erroneous in the model; (4) chemistry and related processes (radiation, deposition, etc.) can induce systematic 


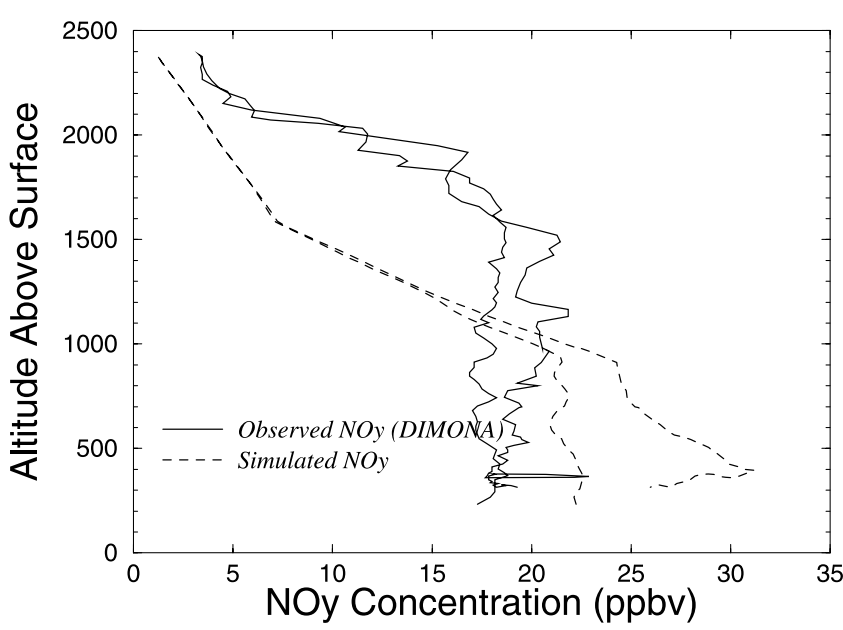

Figure 5. Vertical profiles of $\mathrm{NO}_{y}$ measured aboard DIMONA in the core of the plume of 17 July 1999 (solid lines show ascent and descent) and the corresponding model concentrations (dashed lines). All concentrations are in ppbv.

biases; (5) undersampling problems make comparison statistics uncertain; and (6) measurement errors can affect the estimates. We describe here the methodology used to circumvent these problems.

\subsubsection{Background Concentrations}

[53] In order to cure boundary condition mismatches, we estimate a "background concentration" for each studied species and for each flight by averaging the lowest three concentrations for each flight. This background value is then substracted from all measured concentrations before comparisons are made. The exact same procedure is applied to observations and simulations.

[54] This method has the advantage of simplicity but uses several underlying assumptions: first, it is assumed that the background value does not vary with time and space during each flight; second, it is assumed that the sampling of concentrations around the city is dense enough to allow such an estimation; third, the assumption that concentrations are really higher in the plume than upwind of the city is questionable for very reactive species if oxidation by $\mathrm{OH}$ turns out to be much higher in the plume than elsewhere. While there is no way to verify the correctness of the first two assumptions, the last one can be tested by calculating the correlation between the concentrations of each species and those of a reference, weakly reactive species $\left(\mathrm{NO}_{y}\right.$ or $\mathrm{CO}$ here). If the correlation is high, we expect the assumption to be valid, while nothing can be said when the correlation is low.

[55] These correlations are given for each species in Table 3, both for the observations and for the modelsimulated values, after removal of background values. Correlations with $\mathrm{NO}_{y}$ are calculated using DIMONA flights and correlations with CO using AZTEC flights. For all species, model correlations are quite high but decrease with reactivity. The smallest model correlation is 0.63 and is obtained for the most reactive measured species, propene. For observations, the correlation also decreases with reactivity, but there are a few species (high alcanes, for instance, or propene) for which the low correlation remains unexplained given the fact that these measurements are believed to be reliable. Some species assumed to be measured with low reliability (like benzene for AZTEC) also display low correlations. The lower correlations for observations can also result from a space-time variability of sources not represented in the emission inventory, which is assumed to be valid for a "typical day."

[56] Also shown in Table 3 are the average values of the calculated background concentrations for all species. Remember that model background values for NMVOCs are set to zero, so the corresponding cells in Table 3 are empty. As mentioned above, boundary concentrations of $\mathrm{NO}_{y}$ provided by the large-scale model are overestimated by a factor of 2 , a fact which remains unexplained. CO background concentrations are also overestimated but appear to be less spatially homogeneous than $\mathrm{NO}_{y}$ background values. NMVOC observed background concentrations are in general agreement with those observed in the continental boundary layer. A comparison with concentrations obtained in the British Isles [Photochemical Oxidants Review Group (PORG), 1997] shows that the mean concentration ratios are well reproduced in the upwind ESQUIF measurements.

\subsubsection{Plume Concentrations}

[57] In order to diagnose the emission inventory, model and observed concentrations should be compared only in areas receiving the emissions, hence in the plume of the densely populated area where the concentration signal is largest. We are thus left with only a fraction of all measurements to consider for comparison. Figure 4 provides a qualitative hint about how to define these measurements. We remark that about one-half of the measurements are significantly above the background values. Hence the following criterion has been used to define "plume concentrations": All concentrations are put together into a single set. Then a measurement (or simulated value) is kept as being in the plume when the $\mathrm{NO}_{y}$ (for DIMONA flights) or CO (for AZTEC flights) concentration exceeds the median of the total $\mathrm{NO}_{y}$ or $\mathrm{CO}$ distribution, respectively. Moreover, in order to compare distributions of concentrations using simultaneous values, we keep data which, according to the above definition, belong simultaneously to model and observed plumes. All the following analyses are based on these "plume" values. This leads to a set of 44 concentrations for DIIMONA flights and 23 concentrations for AZTEC flights for each species.

\subsubsection{Comparison Statistics and Model Bias Problems}

[58] If we assume no systematic bias in the model physics and chemistry, simulated plume values should have the same statistical distribution as observed ones if model emissions are correct. We do not have at hand a large ensemble (a few tens of data), hence a single robust measure of this distribution will be used: the median value. It has the advantage of being insensitive to possible outliers, which is not the case with the average value. For a given species $s$, we denote hereafter $\mathrm{OM}_{s}$, the observed median plume value, and $\mathrm{SM}_{s}$, the simulated one.

[59] As suggested by an anonymous reviewer, since the comparisons of medians is not really a standard evaluation method, we also compare for some species $\left(\mathrm{NO}_{y}\right.$ and $\left.\mathrm{CO}\right)$ simulated and observed plume values by means of a twosided regression fit between them, which minimizes, in the 
Table 3. Linear Correlation Coefficients Between Observed NMVOC and $\mathrm{NO}_{y}$ (or $\mathrm{CO}$ ) Concentrations (Background Removed) and Equivalent Numbers for Model Concentrations ${ }^{\mathrm{a}}$

\begin{tabular}{|c|c|c|c|c|c|c|c|c|}
\hline Species & $\begin{array}{c}\text { OBS } \\
\text { Correlation } \\
\text { for } \mathrm{NO}_{y} \\
\end{array}$ & $\begin{array}{c}\text { MOD } \\
\text { Correlation } \\
\text { for } \mathrm{NO}_{y} \\
\end{array}$ & $\begin{array}{c}\text { OBS } \\
\text { Correlation } \\
\text { for } \mathrm{CO} \\
\end{array}$ & $\begin{array}{c}\text { MOD } \\
\text { Correlation } \\
\text { for } \mathrm{CO} \\
\end{array}$ & $\begin{array}{c}\text { OBS } \\
\text { Background } \\
\text { (DIMONA), pptv }\end{array}$ & $\begin{array}{c}\text { MOD } \\
\text { Background } \\
\text { (DIMONA), pptv }\end{array}$ & $\begin{array}{c}\text { OBS } \\
\text { Background } \\
\text { (AZTEC), pptv }\end{array}$ & $\begin{array}{c}\text { MOD } \\
\text { Background } \\
\text { (AZTEC), pptv }\end{array}$ \\
\hline NO $_{y}$ & 1 & 1 & & 0.95 & 3400 & 6100 & & \\
\hline $\mathrm{CO}$ & & 0.98 & 1 & 1 & & & 135,000 & 169,000 \\
\hline Ethane & & & 0.57 & 0.98 & & & 922 & \\
\hline Propane & & & 0.72 & 0.96 & 267 & & & \\
\hline$N$-butane ${ }^{\mathrm{b}}$ & 0.89 & 0.97 & 0.86 & 0.94 & 132 & & 181 & \\
\hline I-butane $\mathrm{e}^{\mathrm{b}}$ & 0.49 & 0.95 & 0.90 & 0.93 & 174 & & 78 & \\
\hline$N$-pentane & 0.89 & 0.94 & 0.90 & 0.93 & 59 & & 59 & \\
\hline I-pentane & 0.91 & 0.95 & 0.76 & 0.95 & 164 & & 155 & \\
\hline$N$-hexane ${ }^{\mathrm{c}}$ & 0.72 & 0.96 & 0.49 & 0.94 & 16 & & 19 & \\
\hline 2-methylpentane & 0.87 & 0.90 & & & 24 & & & \\
\hline 3-methylpentane & 0.58 & 0.90 & & & 90 & & & \\
\hline$N$-heptane & 0.76 & 0.92 & & & 11 & & & \\
\hline $\begin{array}{l}\text { 2methylhexane } \\
+2,3 \text { dimethylpentane }\end{array}$ & 0.77 & 0.89 & & & 15 & & & \\
\hline 3-methylhexane & 0.80 & 0.89 & & & 12 & & & \\
\hline 2,4-dimethylpentane & 0.82 & 0.95 & & & 13 & & & \\
\hline$N$-octane & 0.48 & 0.91 & & & 9 & & & \\
\hline$N$-nonane & 0.21 & 0.89 & & & 12 & & & \\
\hline$N$-decane & 0.87 & 0.87 & & & 11 & & & \\
\hline Ethene & & & 0.69 & 0.92 & & & 169 & \\
\hline Propene & & & 0.13 & 0.63 & & & 61 & \\
\hline Ethyne & & & 0.88 & 0.98 & & & 137 & \\
\hline Benzene $^{c}$ & 0.93 & 0.99 & 0.04 & 0.98 & 109 & & 282 & \\
\hline Toluene & 0.85 & 0.94 & & & 92 & & & \\
\hline$O$-xylene & 0.56 & 0.90 & & & 36 & & & \\
\hline$M+p$-xylenes & 0.83 & 0.82 & & & 17 & & & \\
\hline Ethylbenzene & 0.87 & 0.94 & & & 15 & & & \\
\hline$N$-propylbenzene & 0.16 & 0.95 & & & 13 & & & \\
\hline 1,2,3-trimethylbenzene & 0.33 & 0.74 & & & 11 & & & \\
\hline 1,2,4-trimethylbenzene & 0.19 & 0.74 & & & 49 & & & \\
\hline$M+p$-ethyltoluene & 0.83 & 0.85 & & & 11 & & & \\
\hline$O$-ethyltoluene & 0.27 & 0.80 & & & 10 & & & \\
\hline
\end{tabular}

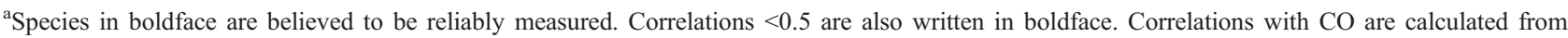
AZTEC flights and correlations with $\mathrm{NO}_{y}$ are calculated from DIMONA flights. OBS is observed and MOD is modeled.

${ }^{\mathrm{b}}$ Uncertain for DIMONA.

${ }^{\mathrm{c}}$ Uncertain for AZTEC.

least squares sense, errors relative to the fitted line in its perpendicular direction, so that the error is not assigned solely to the ordinate. The slope of this fitted line, $\mathrm{SL}_{s}$ (simulation versus observation), is $>1$ when the model overestimates and $<1$ when it underestimates. This statistic generally gives similar results to the median statistic. It will be used only for a few species for comparison.

[60] In order to get rid of possible systematic biases in the transport and mixing processes, we also calculate the ratios of each concentration to a reference, nearly passive one, namely $\mathrm{NO}_{y}$ for DIMONA and CO for AZTEC, for plume data. In the absence of biases from another origin than transport and mixing, the simulated and observed ratios should have a similar distribution. Again, the median of these concentration ratios is used for comparison and is denoted by $\mathrm{OR}_{s, \mathrm{REF}}$ for observations and by $\mathrm{SR}_{s, \mathrm{REF}}$ for simulations, where $s$ is any species and REF is either $\mathrm{NO}_{y}$ or $\mathrm{CO}$.

[61] Finally, in order to quantify the comparisons in an objective manner we use the model/observation ratios for both statistics:
[62] The relative statistics (OR and SR) measure the internal consistency of the inventory but do not evaluate its absolute accuracy. By contrast, the OM, SM, and SL statistics measure possible biases in the emissions if the model has no transport/mixing bias. The presence of such biases can obscure the interpretation of the results. For instance, the combination of a systematic underestimation of mixing with an overestimation of emissions can lead the model to correctly simulated primary species at measurement altitude for the wrong reason. The only way to solve this issue is to make a separate evaluation of transport/ mixing biases, which is done in section 6.1.

[63] Another source of bias comes from chemistry. If, for instance, the $\mathrm{OH}$ concentration calculated by the model is underestimated, the resulting NMVOC oxidation is also underestimated and resulting NMVOC concentrations are overestimated, leading to the wrong conclusion: that the inventory emission of that compound is overestimated. This problem is addressed in a different manner, using sensitivity studies, in section 6.2. Our methodology is therefore to assume temporarily (in section 5) no model biases and to examine in section 6 how such biases could alter the results.

\subsubsection{Estimation Uncertainties}

[64] Nonsystematic (random) model or measurement errors and background estimation create variability in the 
NOy DIMONA

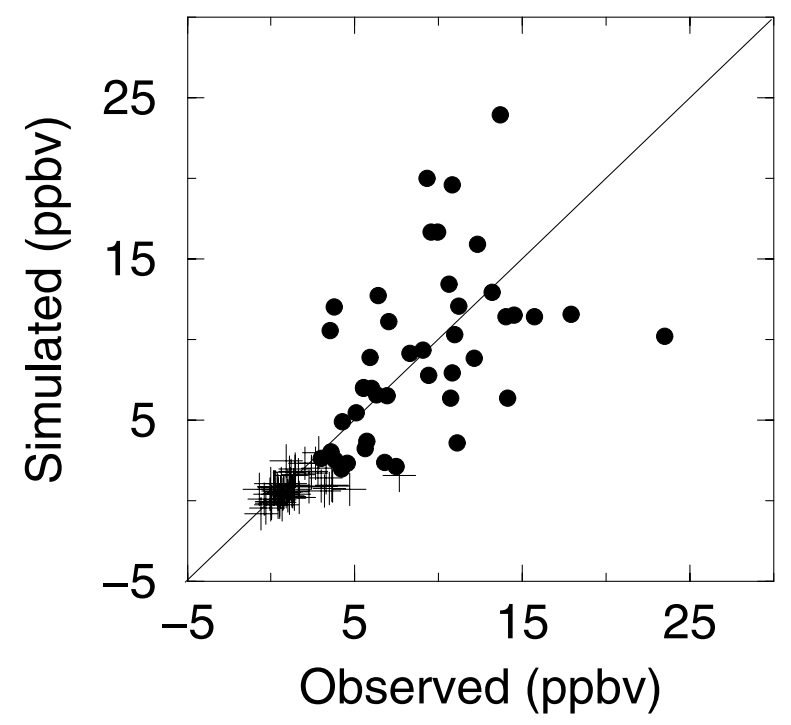

CO AZTEC

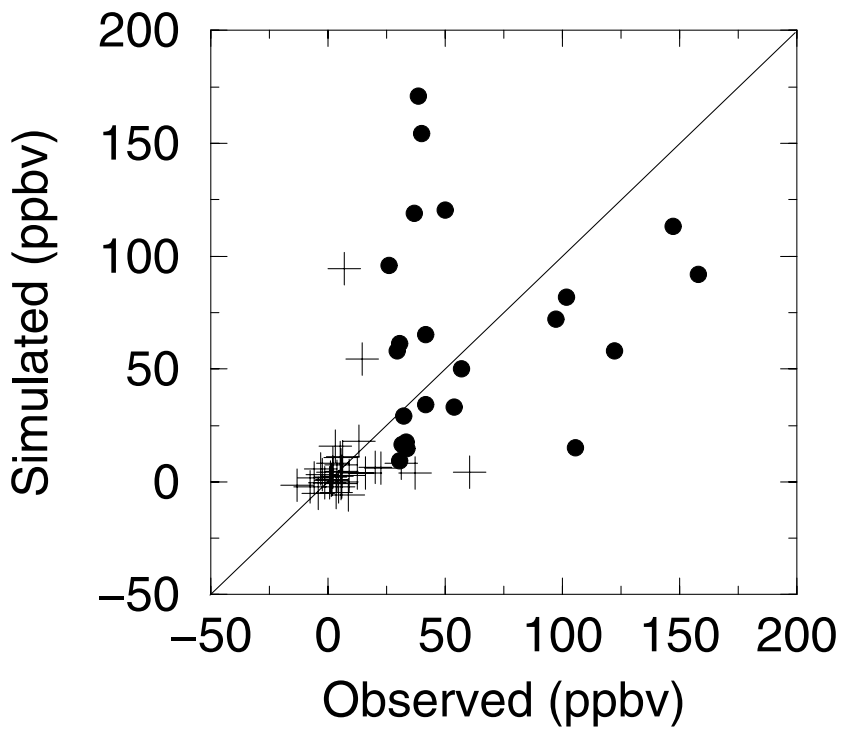

Figure 6. Scatter plots of simulated mixing ratios of $\mathrm{NO}_{y}$ and $\mathrm{CO}$ after removal of the background values for both the model and the observations. Mixing ratios are in ppbv. Aircraft identification is shown on the upper part of both panels. Points selected as "plume data" are marked with a solid circle, and other points are marked with a plus sign.

difference between simulated and observed plume concentrations. This variability, combined with the fact that our sample lengths are finite and short, induces estimation errors in the statistics. In order to quantify the overall uncertainty of our results, we use a "surrogate data" method. All data we use (model or observation) for statistical calculations are simulated using synthetic, randomly generated data, with a distribution whose parameters are fitted to the data. Statistics are then calculated for this synthetic sample. This operation is repeated 1000 times, and the 50th and 950th values give the bounds of the $90 \%$ confidence interval for the results (the equivalent of the 2- $\sigma$ interval for normal distributions).

[65] More precisely, for each flight we assume that the observed reference species $\left(\mathrm{NO}_{y}\right.$ for DIMONA flights and CO for AZTEC flights) has an exponential distribution, where a background value (which depends on the flight) is added. Then we generate a surrogate sample of "synthetic observations" with the same average and background as the data for each flight, using this parametric distribution. Next we need to generate an equivalent sample for model data of the reference species. In order to preserve the correlation between model and observations we do not generate directly synthetic model data (which would be independent from and hence uncorrelated to synthetic observations), but we generate synthetic $\mathrm{NO}_{y}$ or $\mathrm{CO}$ model/observed ratios according, now, to a lognormal distribution whose parameters are calculated from the data and multiply these ratios by the synthetic observation concentrations. Then the same operation is performed with other species, with the constraint of preserving species-to-reference ratios. Synthetic ratios "species/reference" are generated both for model and observations. Finally, 1000 samples of length identical to that of the data are created, and we can calculate all the statistics of section 5.1.3 for each sample and estimate the confidence interval.
[66] Particular care concerning the choice of the parametric distributions is given. If lognormal distributions (for instance) were taken for the observed reference species, one would end up with an incorrect surrogate distribution simply because, in the airborne measurements, there is a high density of values near the background values which cannot be simulated by a lognormal distribution. On the other hand the distributions of model-to-observation reference species ratios are not exponentially distributed, hence the choice of lognormal distributions. We emphasize that this "surrogate data" method of evaluating estimation uncertainties encompasses all causes of random uncertainties, random model deficiencies, background estimates, and measurement random errors.

\subsubsection{Measurement Errors}

[67] The evaluation of absolute measurement errors is detailed in section 2.3. Most of these measurement errors for individual compounds are expected to be in the $10 \%$ range, with a $20 \%$ value as a very conservative estimate. These errors can be either systematic or random so that the full distribution of the errors is hardly known. For that reason, measurement errors are not taken directly into account in the following quantitative study but are considered in the final critical discussion of the comparison results. However, on the basis of experience a few NMVOC species can undergo measurement problems, such as possible coelution or other experimental problems. These species are distinguished in the presentation of results.

\section{2. $\mathrm{NO}_{x}$ and CO Emissions}

[68] Figure 6 (left) shows a scatter diagram of simulated versus observed $\mathrm{NO}_{y}$ ratios after removal of the background values for both model and observations aboard DIMONA. Plume and nonplume data are represented by different symbols. Plume concentrations, produced by regional emis- 
sions, vary from 0 to $\sim 25 \mathrm{ppbv}$. We observe some scatter around the diagonal but no systematic bias. The scatter at high values is an illustration of model (or its input data) "random" deficiencies.

[69] The medians of plume data are $8.7 \mathrm{ppbv}$ for the observations and $8.9 \mathrm{ppbv}$ for the simulations. The $90 \%$ confidence intervals of these estimations are 5.7-9.6 ppbv and 6.2-11.6 ppbv, respectively. Note that the intervals are not necessarily centered around the medians due to the skewedness of the assumed distribution of surrogates. The model/observation ratio is 1.02 with an uncertainty range $0.80-1.52$. We conclude that model values are not significantly higher than observed ones to within about $35 \%$ of uncertainty (by centering the confidence interval). As far as emissions are concerned, we conclude that if there is no model transport/mixing biases, our methodology does not allow us to detect any systematic bias in the $\mathrm{NO}_{x}$ emissions to within $\sim 35 \%$. The slope of the two-sided fit is 1.06 with a confidence interval of $0.81-1.30$, which is consistent with the median statistic result.

[70] Figure 6 (right) shows the scatter diagram of model CO versus observed CO (aboard AZTEC). The medians for plume observations and simulations are 40 and $58 \mathrm{ppbv}$ with ranges of sampling uncertainties of 32-59 and 39121 , respectively. The model/observations ratio is 1.45 with sampling uncertainty ranging from 0.85 to 2.87 . We therefore cannot definitely conclude a significant underestimation or overestimation of the emissions, although emission overestimation is probable unless the model has mixing/ transport biases. The large range here is due to the fewer plume measurements used (23 instead of 44 for DIMONA). The two-sided fit gives a slope of 1.15 with a range of $0.64-1.80$, again consistent with the median estimate.

\subsection{NMVOC Emissions}

\subsubsection{Individual NMVOC Emissions}

[71] We now examine the comparisons between individual NMVOC observed and simulated mixing ratios. Figure 7 (top) shows the scatter diagrams of SM versus OM for all 29 NMVOCs, and Figure 7 (bottom) shows the same scatter diagrams for SR versus OR. Figure 7 also shows the range of sampling uncertainties. In order to distinguish species, Table 4 gives the median values together with the species name.

[72] Both observed and simulated median values vary in a similar range, from a few pptv to about 1 ppbv. The vast majority of molecules is found in low alcanes, benzene, or toluene. The highest observed mixing ratios are found for $n$-butane, $i$-pentane, and ethane, which is also the case for simulated mixing ratios.

[73] The correlation between observed and simulated medians is 0.92 for DIMONA flights and 0.53 for AZTEC flights, indicating that the VOC speciation provided to the model is in fair agreement with observations for the most abundant species. Note that the fewer measurements aboard AZTEC make the median estimations more uncertain than for DIMONA, which probably explains the degradation of the correlation. The assumptions about the surrogate distributions make, for one hydrocarbon (propene, for AZTEC), the median estimate off the confidence interval. For that case these assumptions are, therefore, not appropriate.

[74] For the relative statistics OR and SR, correlations rise to 0.94 for DIMONA flights and 0.71 for AZTEC flights. The confidence intervals shrink in a quite systematic manner. This may be due to the fact that the ratio estimate is insensitive to one of the sources of uncertainty: model random errors in transport and mixing.

[75] In Figure 8, we compare the results for both methods and aircrafts in terms of the model/observation ratios $M$ and $R$. First, we remark that median and ratio statistics are in agreement for each species and for each set of flights. This is an important issue since if $\mathrm{CO}$ emissions are indeed overestimated, as indicated in section 5.2, while NMVOC emissions are not, we should observe a difference between the two estimates in AZTEC flights. Such is not the case, meaning that overestimation of $\mathrm{CO}$ emissions is highly uncertain.

[76] We also remark that the results issued from the two sets of flights are in good agreement for the few "overlapping" species (C4-C6). The differences that could be seen are within the uncertainty ranges.

[77] For most species the confidence interval includes 1, meaning that with the data we have at hand and with the assumption of no systematic model bias, it is not possible to conclude that there are systematic biases in the inventory. Only $n$-hexane, $n$-decane, and $m+p$-xylenes are significantly overestimated, while propane, methylpentanes, methylhexanes, and two C9 hydrocarbons are significantly underestimated. Also, benzene and toluene are underestimated but less significantly. These discrepancies can hardly lead to definite conclusions about where possible errors occur in the inventory. However, at this point, several comments can be given on the basis of the results and of the distribution of mass into activity sectors.

[78] High alcanes (especially $n$-decane) are markedly overestimated. These species are emitted from the use of white spirits. If this bias indeed results from inventory errors, either the total mass of white spirit emissions, their speciation, or both are wrong. Other species, which mainly come from white spirits, are $n$-propylbenzene, trimethylbenzenes, $m+p$-ethyltoluene, and $n$-octane. These latter species do not undergo overestimations like $n$-decane. Thus we suspect that the VOC speciation of white spirits is an important factor for the observed deviations, and more $n$-decane isomers could be emitted instead of $n$-decane.

[79] There are several explanations for the large underestimation of propane emissions. Propane emissions mainly (to $60 \%$ ) stem from propellants. A more intense use of propellants, for example, in spray cans, than anticipated by the model is a possible explanation. Another reason might be the underestimation of the use of propane (liquified petroleum gas) burners. Finally, propane underestimation by a factor 2 to 3 has already been noticed when comparing average hydrocarbon concentrations in the U.K. air quality network $[P O R G, 1993]$ in mostly urban sites with that deduced from emission estimates in field campaign studies in the U.S. [Goldan et al., 1995] or from a model/measurement comparison in Los Angeles, California [Harley and Cass, 1995]. In this latter study, like here, propane was one of the most underestimated species. By contrast, in the EVA experiment around Augsburg [Mannschreck et al., 2002], propane was found overestimated.

[80] The marked overestimation of $n$-hexane is difficult to explain. Nearly $50 \%$ of $n$-hexane emissions in Paris originate from traffic; $35 \%$ come from combustion processes 
DIMONA

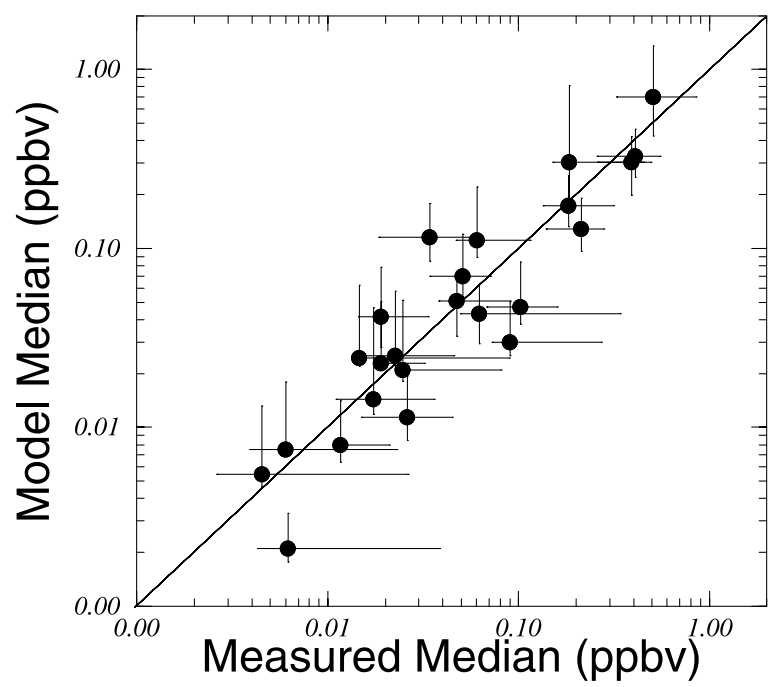

DIMONA

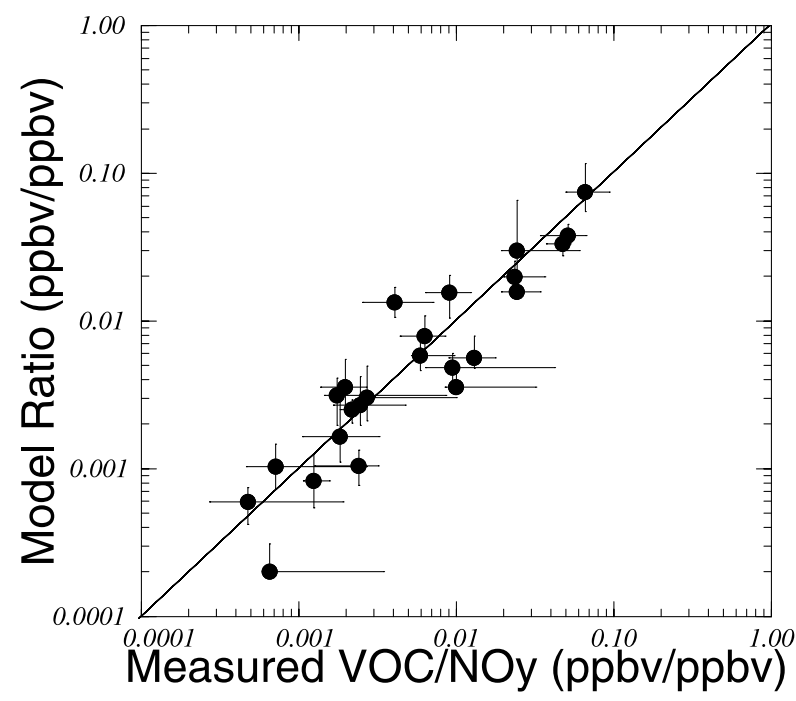

AZTEC

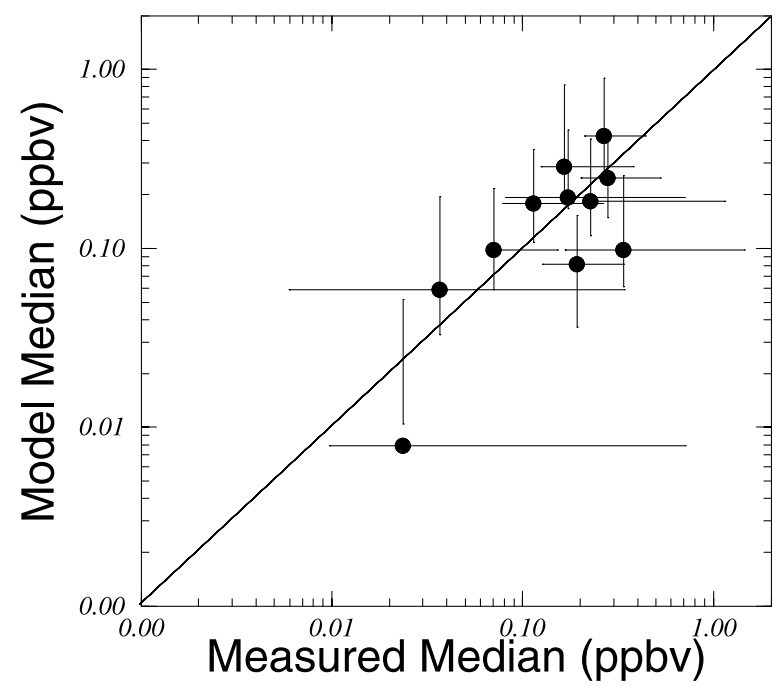

AZTEC

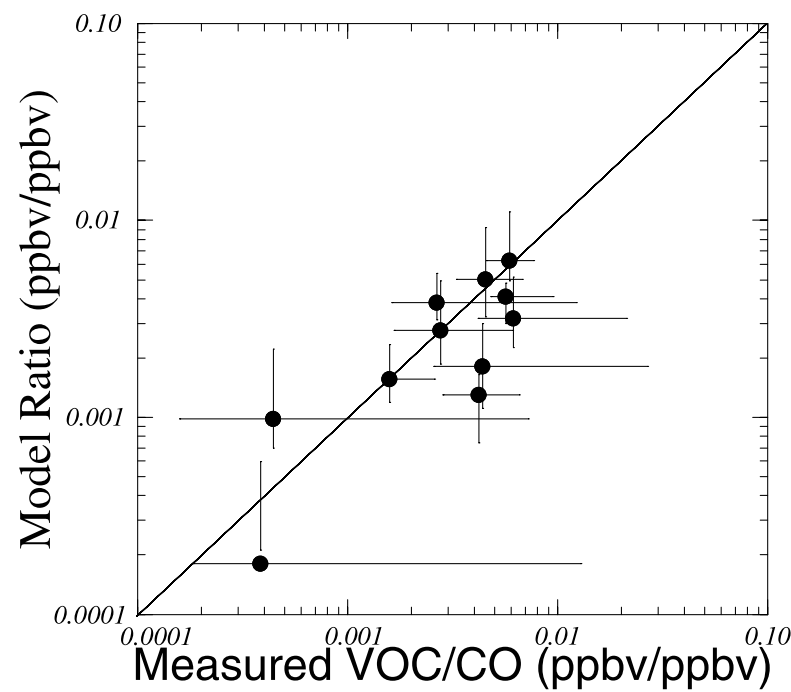

Figure 7. (top) Scatter diagrams of the median values, simulated versus observed, for all the 29 individual NMVOCs. Uncertainty ranges are marked by segments of lines. The left panel is for species measured aboard DIMONA, and the right panel is for species measured aboard AZTEC. (bottom) As for Figure 7 (top), but for $\mathrm{NMVOC} / \mathrm{NO}_{y}$ or $\mathrm{NMVOC} / \mathrm{CO}$, depending on the aircraft used.

and $8 \%$ from solvent use. As the hexane isomers 2-methylpentane and 3-methylpentane, which mainly stem from traffic, are significantly underestimated, this may hint at a speciation error for road transport. Also, combustion processes are correlated with the ambient temperature, so the lack of account of time variation for temperature in the inventory may result in an overestimation of combustion emissions during days warmer than average (an average July temperature profile was used in the emission model). The latter might also be a reason for the overestimation of ethylbenzene.

[81] Finally, benzene and $o$-ethyltoluene, mainly caused by evaporation processes (including unburned fuel), are significantly underestimated, and the same holds for methylpentanes. The evaporation of gasoline vapor from gasoline tanks of older vehicles is caused by temperature changes, especially increases in temperature. Again, the lack of temperature dependence in the emission model may be responsible for these problems.

\subsubsection{Grouped NMVOC Emissions}

\subsubsection{Total NMVOC Mass}

[82] We now address the question of whether the total inventory mass of emitted NMVOCs is compatible with the measurements. This is an important question since its answer will assess the total NMVOC inventory independently of the VOC speciation. Since these measurements are not performed on all species but on roughly $50 \%$ of them in terms of mass (see section 2.3), we cannot evaluate the total mass but only the summed mass of measured compounds. Moreover, we do not observe "intact" NMVOCs but 
Table 4. Median Plume Values (Background Removed) for Observed and Simulated NMVOC Concentrations and for the Two Sets of Airborne Measurements ${ }^{\mathrm{a}}$

\begin{tabular}{|c|c|c|c|c|c|c|}
\hline Species & $\begin{array}{c}\text { Median OBS } \\
\text { (DIMONA) }\end{array}$ & $\begin{array}{c}\text { Median MOD } \\
\text { (DIMONA) }\end{array}$ & $\begin{array}{c}\text { Median OBS } \\
\text { (AZTEC) }\end{array}$ & $\begin{array}{c}\text { Median MOD } \\
\text { (AZTEC) }\end{array}$ & $\begin{array}{l}\text { Oxidized Fraction } \\
\text { Estimate } \\
\text { (DIMONA), \% }\end{array}$ & $\begin{array}{c}\text { Oxidized Fraction } \\
\text { Estimate } \\
\text { (AZTEC), \% }\end{array}$ \\
\hline Ethane & & & 280 & 246 & & 2 \\
\hline Propane & & & 193 & 82 & & 8 \\
\hline$N$-butane $^{\text {b }}$ & 510 & 705 & 267 & 423 & 7 & 20 \\
\hline I-butane $\mathrm{e}^{\mathrm{b}}$ & 184 & 304 & 114 & 179 & 8 & 22 \\
\hline$N$-pentane & 183 & 173 & 70 & 98 & 13 & 24 \\
\hline$I$-pentane & 409 & 329 & 227 & 184 & 11 & 25 \\
\hline$N$-hexane ${ }^{c}$ & 34 & 116 & 37 & 59 & 17 & 33 \\
\hline 2-methylpentane & 102 & 47 & & & 23 & \\
\hline 3-methylpentane & 90 & 30 & & & 23 & \\
\hline$N$-heptane & 17 & 14 & & & 24 & \\
\hline 2methylhexane +2 ,3dimethylpentane & 26 & 11 & & & 20 & \\
\hline 3-methylhexane & 12 & 8 & & & 22 & \\
\hline 2,4-dimethylpentane & 19 & 23 & & & 23 & \\
\hline$N$-octane & 5 & 5 & & & 25 & \\
\hline$N$-nonane & 15 & 24 & & & 30 & \\
\hline$n$-decane & 19 & 42 & & & 22 & \\
\hline Ethene & & & 173 & 192 & & 40 \\
\hline Propene & & & 24 & 8 & & 68 \\
\hline Ethyne & & & 165 & 286 & & 6 \\
\hline Benzene $^{c}$ & 212 & 128 & 338 & 98 & 4 & 11 \\
\hline Toluene & 392 & 302 & & & 16 & \\
\hline$O$-xylene & 47 & 51 & & & 29 & \\
\hline$M+p$-xylenes & 60 & 111 & & & 48 & \\
\hline Ethylbenzene & 51 & 70 & & & 18 & \\
\hline$N$-propylbenzene & 62 & 43 & & & 19 & \\
\hline 1,2,3-trimethylbenzene & 6 & 8 & & & 54 & \\
\hline 1,2,4-trimethylbenzene & 25 & 21 & & & 51 & \\
\hline$M+p$-ethyltoluene & 23 & 25 & & & 42 & \\
\hline$O$-ethyltoluene & 6 & 2 & & & 28 & \\
\hline
\end{tabular}

${ }^{a}$ Median plume values are in pptv. Species in boldface denote species for which measurements are believed to be reliable. In columns 2,3 , 4 and 5 , boldface is used to highlight concentrations which differ by more than a factor 2 between simulations and observations. Columns 6 and 7 show the fraction of oxidized NMVOC for DIMONA and AZTEC flights, respectively (see the text for further explanation). OBS is observed and MOD is modeled.

${ }^{\mathrm{b}}$ Uncertain for DIMONA.

${ }^{\mathrm{c}}$ Uncertain for AZTEC.

oxidized NMVOCs. In order to group several VOCs into classes by summing up concentrations, one has to weight them by the inverse of the fraction of molecules that has not been oxidized. Finally, since observations are mixing ratios and not mass, individual hydrocarbon mixing ratios are weighted by their molar mass in the sum.

[83] The estimation of the reacted fraction, which actually depends on the measurement proximity to the city, is achieved by performing a new model integration for the individual NMVOCs with the assumption that $\mathrm{OH}$ is identically zero. Then, again, the same statistics as above are calculated with these new simulated sets. The median values $(\mathrm{OM})$ obtained are divided by those of the base case simulation with nonvanishing $\mathrm{OH}$. This ratio gives an estimate of the inverse of the NMVOC emission fraction that has not been oxidized at measurement time. It is used as a weight applied to both simulated and observed NMVOC concentrations.

[84] The oxidized fractions are reported in Table 4. They vary from a few percent (for ethane) to $68 \%$ (for propene). Note also the difference of reacted fraction between the two flight sets, which can be explained by the fact that AZTEC measurements were generally taken farther from sources than DIMONA ones.

[85] For DIMONA the mass results give a model/observation ratio of 1.01 with the median statistics and 0.84 with the $R$ statistics with $90 \%$ confidence intervals of $0.60-1.42$ and $0.56-1.22$, respectively. Therefore there is no apparent bias, nor any inconsistency between $\mathrm{NO}_{x}$ and total measured NMVOC emissions, to within $\sim 40 \%$.

[86] AZTEC results differ slightly since the median model/observation ratio is 0.72 with a confidence interval of $0.20-1.34$. The equivalent numbers for the species/CO ratio statistics are 0.76 with a confidence interval of $0.24-$ 2.41. The confidence intervals are very large and show that the model/observation differences cannot be significantly assessed.

[87] We conclude that we cannot detect any inconsistency in the emissions between $\mathrm{NO}_{x}, \mathrm{CO}$, and NMVOCs. This is of particular importance since ozone production is governed, in urban areas, by the NMVOC/NO $\mathrm{Natios}_{x}$

\subsubsection{Total Reactivity}

[88] We now evaluate the total reactivity of the inventory by comparing propene-equivalent emitted masses. We sum up, both for simulations and observations, the mixing ratios for all individual compounds, corrected by the nonreacted fraction and weighted by the reactivity relative to $\mathrm{OH}$. As before, the model/observation ratios of the two statistics are calculated for the measured compounds only.

[89] For DIMONA species the model/observation $M$ statistics ratio is 0.94 with a $0.46-1.33$ confidence interval; the $R$ statistics ratio is 0.85 with a $0.44-1.20$ interval. For AZTEC the corresponding ratios are 0.52 and 0.81 with large intervals of $0.05-13.1$ and $0.05-11.6$, respectively. 


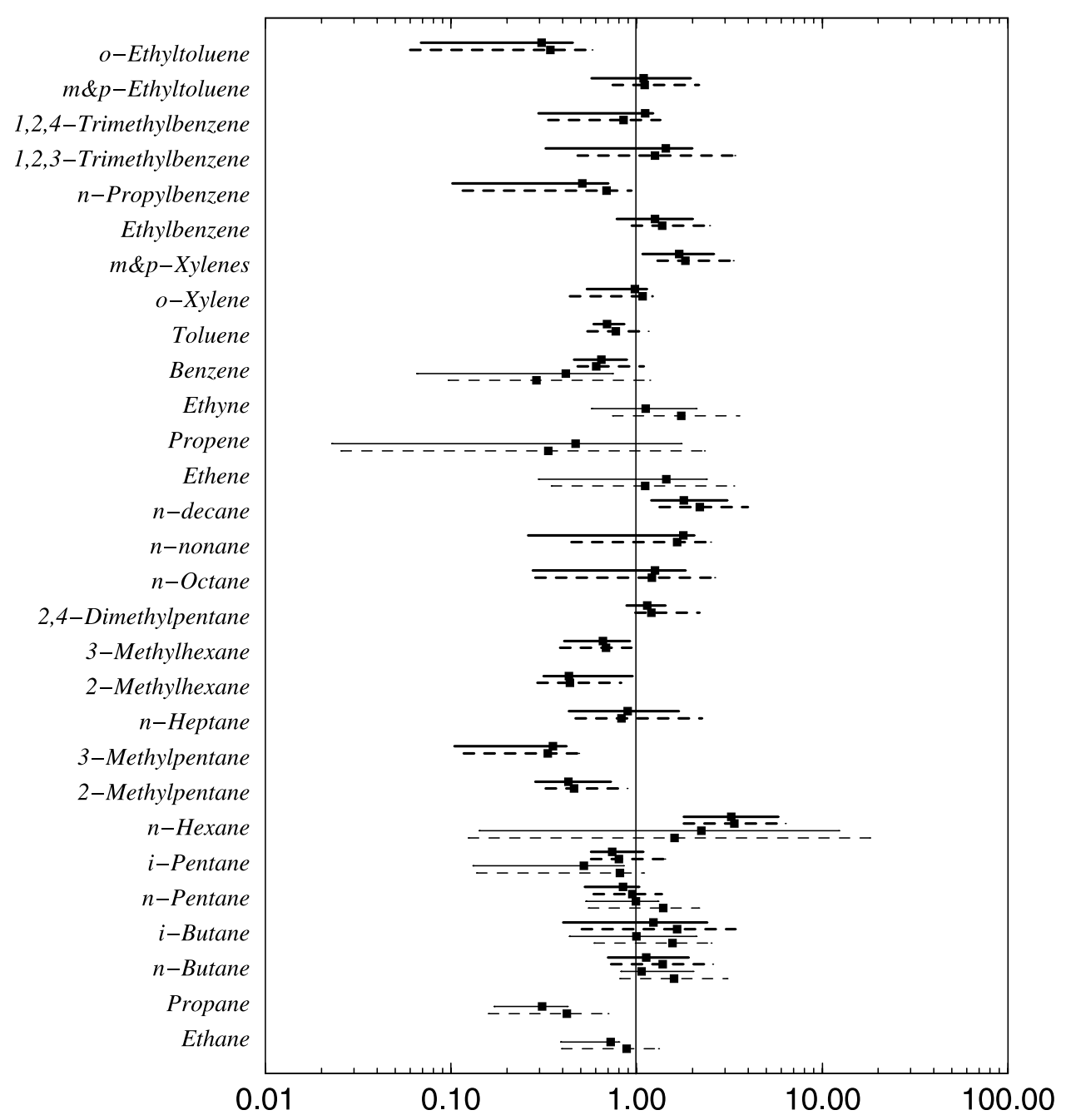

Figure 8. Simulated/observed ratios of the two statistics (median concentrations, dashed lines; median NMVOC/NO $\mathrm{NO}_{y}$ or NMVOC/CO ratios, solid lines), displayed as bold squares, with their associated $90 \%$ uncertainty ranges (lines) for all studied NMVOCs and for the two sets of flights (DIMONA, bold lines; AZTEC, shaded lines). Values $>1$ indicate a model overestimation and values $<1$ indicate an underestimation.

Clearly, nothing can be concluded about reactivity from AZTEC flights because the most reactive species are also the most uncertain. By contrast, with DIMONA measurements, one concludes that the reactivity of the inventory is consistent with that observed to within $\sim 40 \%$. Nevertheless, we have to remember here that the measured species are not fully representative of the overall reactivity of the inventory (see section 2.3). Particularly reactive alkenes have not been taken into account in DIMONA measurements.

\section{Discussion}

[90] In section 5, comparisons between simulated and observed concentrations have been carried out. $R$ statistic results have shown that there is internal consistency between $\mathrm{NO}_{x}, \mathrm{CO}$, and NMVOC emissions to within the accuracy provided by the limited samples of data. $M$ statistic results showed that if we make the assumption that there is no systematic model bias, the emissions are also unbiased to within a certain accuracy (roughly $35 \%$ for $\mathrm{NO}_{y}, 40 \%$ for measured NMVOCs, and a factor of 2 for CO). These $90 \%$ confidence intervals account for all sorts of random errors together (model, observations, background values, etc.).

[91] Here we now address the sources of possible systematic model bias which could alter the results from section 5. In the model formulation, two sources of bias are investigated: bias due to wrong vertical mixing and bias in the chemistry. Possible biases due to horizontal transport should, in principle, be minor as compared to vertical mixing since the latter is highly parameterized, using a $K$ diffusion formulation [see Schmidt et al., 2001], while horizontal winds are directly taken from ECMWF data. Hence horizontal transport biases are not considered here.

[92] Measurements can also contain biases. These will be discussed very briefly in section 6.3 .

\subsection{Biases From Mixing}

[93] Biases from mixing can stem from two different factors: biases in the boundary layer height and biases in the turbulent transport within the boundary layer. In order to 
test the latter source of bias we performed a sensitivity test by multiplying and dividing the diffusivity coefficient by 2 and recalculating the median and ratio statistics. Quite surprisingly, the model response to such changes is very weak (a few percent), much weaker than the range uncertainty provided by the confidence intervals of section 5, essentially due to the following facts: when changing diffusivity, one increases both polluted fluxes from below but also outgoing fluxes to above in the third model layer at altitudes where measurements were taken.

[94] By contrast, model results are more sensitive to the BLH. The model BLH is estimated from ECMWF profiles of virtual potential temperature and wind as the height where the Richardson number equals a critical value, namely 0.15 . This rough estimate, together with the low vertical resolution, can potentially lead to significant errors in the model mixing representation.

[95] In order to test the sensitivity of our results to BLH biases we perform a new experiment in which the original depth of the boundary layer is increased by $30 \%$ (this value will be justified below) but other parameters are unchanged all along the simulations. The response of the simulated concentrations to this change varies from one species to another. In general, plume medians are reduced by a factor ranging between 10 and $40 \%$. The $\mathrm{NO}_{y}$ reduction is only $\sim 20 \%$ with about the same uncertainty range, which still provides consistency between model and observations to within $\sim 35 \%$. The fact that this reduction value does not correspond exactly to the increase factor in the BLH is not surprising since $\mathrm{NO}_{y}$ is not a fully conserved species family. For instance, nitric acid has a high deposition rate. Deposition of nitrogen dioxide can also play a role. Increasing the BLH also changes the vertical distribution of turbulent diffusivity in the model. For NMVOCs we find, on average, a reduction of plume medians of $\sim 30 \%$.

[96] Despite these differences, the qualitative conclusions of section 5 hold; the same NMVOCs are found significantly overestimated or underestimated because the ranges of uncertainties are much larger than $30 \%$.

[97] In an attempt to verify whether such a systematic bias is present in the model BLH we compare the latter with backscatter lidar measurements of the BLH taken on Site Instrumental de Recherche par Teledetection Atmospherique (SIRTA), Palaiseau, $25 \mathrm{~km}$ south of Paris in a less urbanized area during the IOP days. The backscatter lidar used in this study operates at $0.53 \mu \mathrm{m}$ and the signal is extremely sensitive to particles with radii between 0.1 and $1 \mu \mathrm{m}$. Once they have been stripped from the surface, aerosols are trapped in the boundary layer by the capping temperature inversion. As a result, the lidar signal is generally observed to be large in the boundary layer and to decrease rapidly above [e.g., Fochesatto et al., 2001]. The top of the boundary layer is characterized by large gradients of the aerosol content. We define the local BLH as the base of the transition zone (i.e., the top of the mixed layer) using a gradient algorithm [Dupont et al., 1994]. The accuracy of the estimated BLH is $\sim 30 \mathrm{~m}$. In order to remove high-frequency fluctuations in the BLH, lidar measurements are averaged over full hours. We keep only convective hours for comparisons, from 1000 UT to $1700 \mathrm{UT}$.

[98] Figure 9 shows a scatter diagram representing lidar BLH versus model BLH. There is a fair correspondence, but

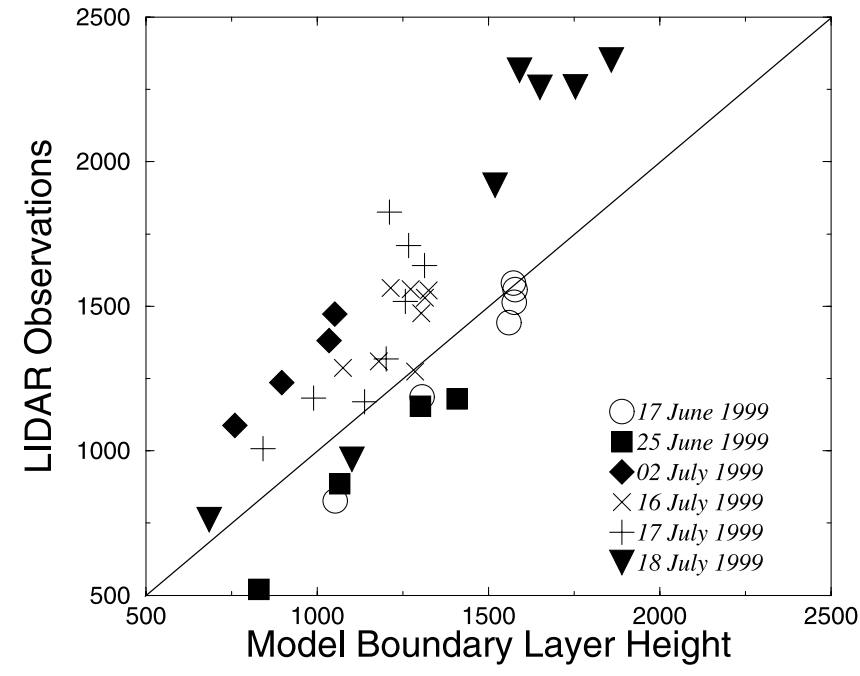

Figure 9. Observed boundary layer height (using the backscatter lidar) versus model boundary layer height for most intense observation period days, between 1000 UT and 1700 UT when measurements were available. Lidar measurements are averaged over full hours.

as suspected in section 4 , the BLH is significantly underestimated during 16-18 July (IOP 6). More generally, during July IOP days, the BLH is underestimated by $30 \%$, while for June measurements, the model BLH is rather overestimated.

[99] Since most airborne measurements were carried out in July, an estimation of a $30 \%$ bias in the BLH is a conservative estimation for our purposes, and according to the above sensitivity experiment, we do not expect qualitative changes in the results of section 5 .

\subsection{Biases From Chemistry}

[100] It would be a tremendous task to document all possible uncertainties in the numerical representation of chemistry (and related processes like deposition) in the model. They may arise from inaccurate estimations of chemical constants, hydrocarbon lumping, radiation effects on photolysis, or deposition velocities of key species such as ozone. Nevertheless, all these inaccuracies would finally result in erroneous concentrations of the hydroxyl radical $\mathrm{OH}$, which is the only important parameter in the estimation of simulated NMVOC concentrations.

[101] In order to test the sensitivity of our results to all these uncertainty sources we simply perform two new numerical experiments by uniformly multiplying $(\mathrm{OH} \times 2$ scenario) and dividing $(\mathrm{OH} / 2$ scenario) the $\mathrm{OH}$ concentration provided by the model by two and recalculating the NMVOC concentrations with each of these assumptions. In this way we hope to obtain a conservative estimate of the possible range of results that could be obtained due to chemistry inaccuracies. In these new simulations, since there is no feedback of the $\mathrm{OH}$ change onto photochemistry (only NMVOCs are changed), we expect a monotonic relation between $\mathrm{OH}$ and NMVOCs: if $\mathrm{OH}$ is increased, NMVOCs must decrease at each grid point.

[102] Figure 10 shows, as in Figure 8, the model/observation ratios $M$ and $R$ for the control experiment, with error 


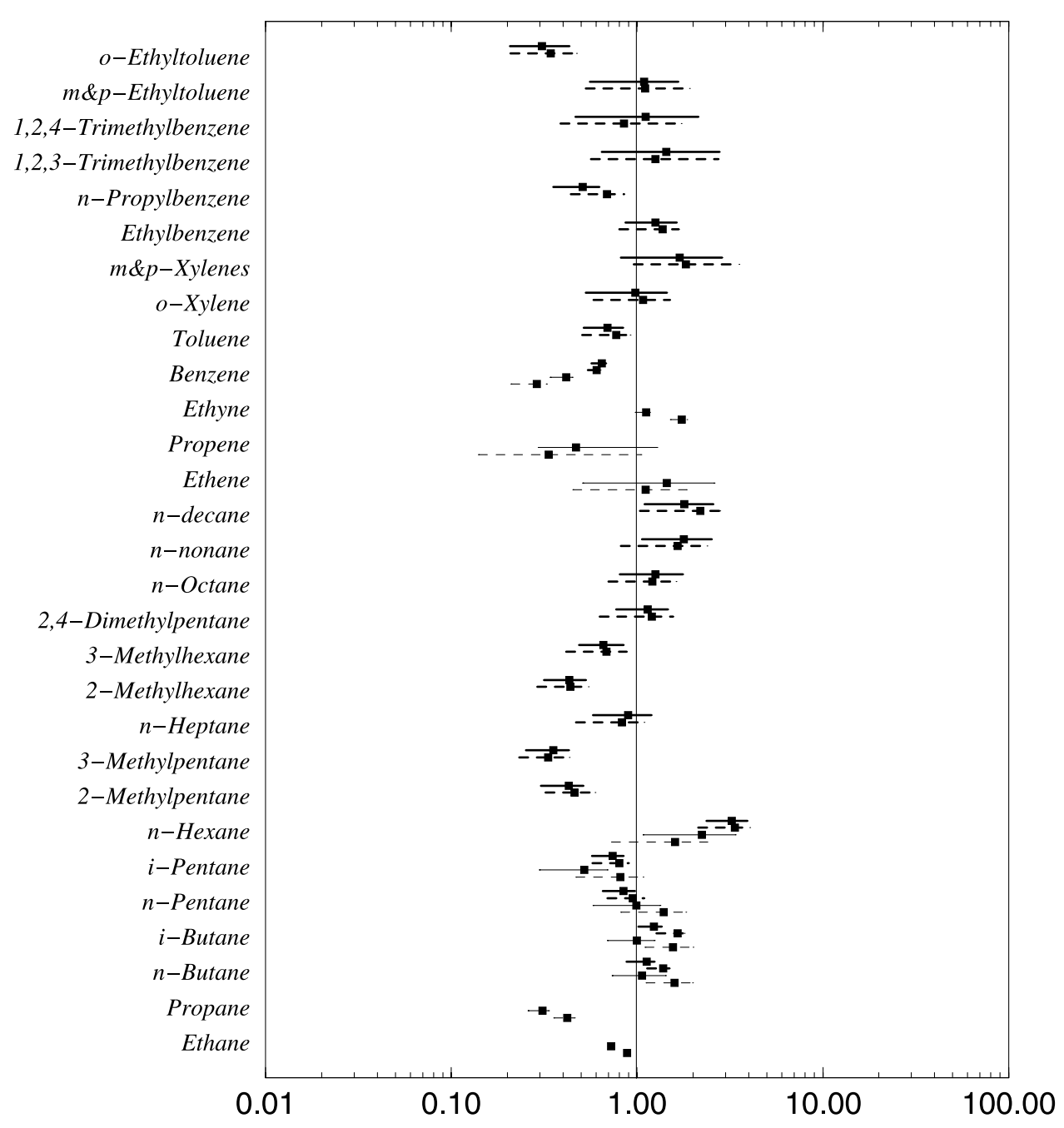

Figure 10. As in Figure 8, but now the lines link the ratios obtained for the $\mathrm{OH} \times 2$ scenario (left end) and for the $\mathrm{OH} / 2$ scenario (right end).

bars now indicating the range span that the results would obtain by varying $\mathrm{OH}$ between 0.5 and 2 times its original value instead of indicating the sampling uncertainty range. This range depends exclusively on the reactivity of the hydrocarbon: the more reactive, the larger the range. We remark that the ranges are smaller than or equivalent to the sampling uncertainties ranges.

[103] The extreme scenarios of double and half $\mathrm{OH}$ are, however, not realistic by themselves. In several studies [Forberich and Comes, 1997; Crosley, 1997], model OH radicals have been found biased relative to observations by no more than $50 \%$. If we assume the less dramatic change in $\mathrm{OH}$ concentrations of $50 \%$ instead of $100 \%$, we end up with ranges which, in the worst case, are always smaller than the confidence interval (not shown). The overall conclusion of these sensitivity experiments is that in the above diagnostics, sampling errors dominate possible model biases.

\subsection{Measurement and Other Biases}

[104] The impact of measurement biases on the results has not been taken into account here. However, as mentioned in section 2, measurement errors should not exceed $20 \%$, taking into account random and systematic errors. In the worst case, all measurements are biased, and yet these errors do not change our results qualitatively since the $90 \%$ confidence intervals are usually at least twice as large.

[105] However, it has to be mentioned that the DIMONA $\mathrm{NO}_{y}$ measurements do not include organic nitrates in the form of aerosols, and the model does not take into account nitrate aerosol formation. This is not really a measurement bias but rather a potential bias in the interpretation of measurements. If a large fraction of nitrogen compounds is converted into aerosols in the city plume and if the $\mathrm{NO}_{x}$ emission inventory is correct, one should obtain less observed $\mathrm{NO}_{y}$ than modeled. Since such is not the case, one would conclude that $\mathrm{NO}_{x}$ emissions have a negative bias that compensates this lack of aerosol formation of the model. We are unable, using this model, to solve this issue quantitatively.

\section{Conclusion}

[106] The aim of this paper was to demonstrate the possibility of quantitatively evaluating a regional emission inventory from a series of airborne measurements and simulations using a three-dimensional chemistry transport 
model. The concerned region is the area around greater Paris and the measurements were taken during the ESQUIF [Menut et al., 2000] field campaign. The assessment of the inventory is based on $\mathrm{NO}_{x}, \mathrm{CO}$, and a few tens of individual hydrocarbons. However, airborne-measured mixing ratios provide only an integrated picture of the emissions. Only global quantities such as the sum of morning emissions in the Paris area and its suburbs can be diagnosed, on average, over several flights. Time and space distributions cannot be distinguished using such an approach.

[107] Two methods have been used for model/observations comparisons: an absolute method, which directly compares the observed and simulated distributions of mixing ratios, and a relative method, which compares ratios to a reference, weakly reactive species. We have also estimated the uncertainties of the results due to the combination of model/measurements random errors and finite sampling of the plume by the airborne measurements. These uncertainties, usually larger than $30-40 \%$, dominate the estimated uncertainties of measurements $(<20 \%)$.

[108] Since there can be error compensation between model and emission biases, we have performed a series of sensitivity experiments in order to quantify the impacts of such possible biases in the model formulation. Particular care is given to potential biases arising from a wrong estimation of the boundary layer height (BLH). A comparison of simulated BLH with backscatter lidar measurements shows that the model often underestimates the BLH but not by more than $30 \%$ on average. We verify that the presence of such a bias cannot qualitatively alter our results. Emphasis has also been put on potential chemical biases, and sensitivity experiments have shown that these also cannot alter the qualitative aspects of our results simply because the induced changes are most often much smaller than the estimate uncertainty ranges.

[109] In summary, it is found that $\mathrm{NO}_{x}$ emissions are compatible with airborne measurements to within $35 \%$; total measured hydrocarbon emissions are also consistent with measurements to within $40 \%$. CO emissions are $\sim 45 \%$ higher than what one would expect from measurements but with a factor of 2 of uncertainty. This certainly does not allow us to definitely conclude the existence of any bias in $\mathrm{CO}$ emissions. Simulated reactivity due to measured hydrocarbons is in agreement with that observed, also to within $\sim 40 \%$. We also remark that measured hydrocarbons account only for about half of the emitted mass and for $40 \%$ of the total reactivity. This does not allow us to draw definitive conclusions about the total volatile organic compounds emission inventory.

[110] Contrasted results are obtained for individual hydrocarbons. For most species measured, agreement is found between model and observations to within a factor 2 . For those species exhibiting strong discrepancies, tentative interpretations are given. It is suggested, for instance, that activities involving propane and evaporation processes are underestimated, whereas with regard to the use of white spirits, there is a speciation problem and/or an overestimation. The error in speciation from solvent use emissions is presumably larger than from traffic emissions due to a weaker database. More detailed information from the solvent-producing industry or from solvent consumption would be needed to improve the hydrocarbon split.
[111] Quite interestingly, our model/observation comparison results for individual hydrocarbons provide figures in the same range of errors as previous studies. For instance, Harley and Cass [1995] found that most hydrocarbons were predicted within a factor of 2 , like here, and they estimated a mean departure from model to observations of $\sim 40 \%$ for total hydrocarbons. Using the same measure of model/ observation error, we obtain here an estimated mean departure of $50 \%$.

[112] The results presented here can provide useful diagnostics in order to investigate the source of possible errors in the inventory. They give directions of search but cannot be used directly. For instance, the question of whether the errors could arise from a bad estimation of some activity sectors emission totals or from their hydrocarbon speciation cannot be solved since the problem is largely underdetermined: much more data are required to achieve that degree of diagnostics since the number of parameters is huge.

[113] Finally, we emphasize that the limiting factor in our diagnostics is the small size of the samples. To reduce the uncertainties further, we need more systematic measurements. The practice of routine measurements for $\mathrm{NO}_{x}$ or NMVOCs by air quality monitoring networks could help in that sense, but usually these measurements are taken at ground level and may be influenced by local factors that weaken their representativeness. We also expect model inaccuracies to be larger near the ground due to the many parameterizations of surface processes. Systematic airborne measurements are, by contrast, very expensive. The space for research in experimental setups which meet the two conditions, representativeness and low cost, for accurate monitoring of primary emissions at the scale of a large city is still open.

[114] Acknowledgments. This study has been supported by the French Ministry of Environment and by the regional council of the Ile-de-France region. We would like to acknowledge Sanford Sillman for fruitful discussions, Laurent Menut, Hauke Schmidt, and Patrick Raberanto for their help in the processing of data and models, and the many collaborators who worked with us during the ESQUIF project. We are also thankful to Mété France and the European Center for Medium-Range Weather Forecasts (ECMWF) for leaving us free access to the meteorological database which allowed model simulations. Suggestions from two anonymous reviewers were very helpful in improving the quality of the work and the manuscript.

\section{References}

ARIA Technologies, Simulations météorologiques sur la région Ile-deFrance durant l'épisode de pollution photochimique du10 au 13 août 1997, Rep. ARIA/2000.096, Paris, 2000.

Atkinson, R., Gas-phase tropospheric chemistry of volatile organic compounds: Alkanes and alkenes, J. Phys. Chem. Ref. Data, 26, 215-290, 1997.

Atkinson, R., D. L. Baulch, R. A. Cox, R. F. Hampson, J. A. Kerr, J. M. Rossi, and J. Troe, Evaluated kinetic, photochemical and heterogeneous data for atmospheric chemistry, IUPAC Subcommittee on Gas Kinetic Data Evaluation for Atmospheric Chemistry, J. Phys. Chem. Ref. Data, 26, suppl. 5, 521-1012, 1997.

Becker, A., E. Schaller, and K. Keuler, Continuous four-dimensional source attribution for the Berlin area during two days in July 1994. part I: The new Euler-Lagrange-model system LaMM5, Atmos. Environ., 35, 54975508, 2002.

Boissard, C., Distributions troposphériques globales des hydrocarbures légers: De l'expérimentation à la modélisation, Ph.D. thesis, Univ. Paris VII, France, 1992.

Bonsang, B., and G. Lambert, Nonmethane hydrocarbons in an oceanic atmosphere, J. Atmos. Chem., 2, 257-271, 1985.

Bourdeau, B., Evolution du parc automobile français entre 1970 et 2020, Rep. 9801, Lab. Energ. et Nuisance, Chambery, France, 1998. 
Chang, M. E., D. E. Hartley, C. Cardelino, D. Haas-Laursen, and W.-L. Chang, On using inverse methods for resolving emissions with large spatial inhomogeneities, J. Geophys. Res., 102, 16,023-16,036, 1997.

Centre Interprofessionnel Technique d'Etudes de la Pollution Atmosphérique, Inventaires d'émissions dans l'atmosphère dans le cadre des plans régionaux de la qualité de l'air-Région Ile de France, paper presented at Convention 14/96, AIRPARIF, Paris, France, 1997.

Corsmeier, U., et al., Ozone and PAN formation inside and outside of the Berlin plume: Process analysis and numerical process simulation, J. Atmos. Chem., 42, 289-321, 2002.

Crosley, D. R., Tropospheric OH Photochemistry Experiment: A summary and perspective, J. Geophys. Res., 102, 6495-6510, 1997.

Dupont, E., J. Pelon, and C. Flamant, Study of the moist convective boundary layer structure by backscatter lidar, Boundary Layer Meteorol., 69, $1-25,1994$.

Fochesatto, J., P. Drobinski, C. Flamant, D. Guedalia, C. Sarrat, P. H. Flamant, and J. Pelon, Evidence of dynamical coupling between the residual layer and the developing convective boundary layer, Boundary Layer Meteorol., 99, 451-464, 2001.

Forberich, O., and F. J. Comes, Local concentration of the tropospheric oxidants $\mathrm{OH}$ and $\mathrm{O}_{3}$ : Measurement and interpretation, J. Chem. Soc. Faraday Trans., 93, 2899-2915, 1997.

Friedrich, R., and S. Reis (Eds.), Emissions of Air Pollutants: Measurements, Calculations, Uncertainties-Results From the EUROTRAC Subproject GENEMIS, Springer-Verlag, New York, in press, 2003.

Goldan, P. D., M. Trainer, W. C. Kuster, D. D. Parrish, J. Carpenter, J. M. Roberts, J. E. Yee, and F. C. Fehsenfeld, Measurements of hydrocarbons, oxygenated hydrocarbons, carbon monoxide, and nitrogen oxides in an urban basin in Colorado: Implications for emission inventories, J. Geophys. Res., 100, 22,771-22,783, 1995.

Gros, V., Etude des variabilités de l'ozone et du monoxyde de carbone dans la couche limite atmosphérique marine de l'hémisphère sud, Ph.D. thesis, 211 pp., Univ. Paris VII, France, 1998.

Hannah, S. R., J. C. Chang, and M. E. Fernau, Monte Carlo estimates of uncertainties in predictions by a photochemical grid model (UAM-IV) due to uncertainties in input variables, Atmos. Environ., 32, 3619-3628, 1998.

Harley, R. A., and G. R. Cass, Modeling the atmospheric concentrations of individual volatile organic compounds, Atmos. Environ., 29, 905-922, 1995.

Hassel, D., F.-J. Weber, and T. Schmitz, Zusammensetzung der Kohlenwasserstoffe im Abgas unterschiedlicher Fahrzeugkonzepte, 1999, Rep. JÜL3457, Forschungszentrum, Jülich, Germany, 2000.

Hauglustaine, D. A., G. P. Brasseur, S. Walters, P. J. Rash, J.-F. Müller, L. K. Emmons, and M. A. Carroll, MOZART, a global chemical transport model for ozone and related chemical tracers: 2. Model results and evaluation, J. Geophys. Res., 103, 28,291-28,336, 1998.

Hov, O., F. Stordal, and A. Eliassen, Photochemical oxidant control strategies in Europe: A 19 day case study using a Lagrangian model with chemistry, Rep. TR5/95, Norw. Inst. for Air Res., Lillestrom, Norway, 1985.

Jenkin, M. E., S. M. Saunders, and M. J. Pilling, The tropospheric degradation of volatile organic compounds: A protocol for mechanism development, Atmos. Environ., 31, 81-104, 1997.

Kanakidou, M., B. Bonsang, and G. Lambert, Light hydrocarbons, vertical profiles and fluxes in a French rural area, Atmos. Environ., 23, 921-927, 1989.

Kleinman, L. I., P. H. Daum, D. G. Imre, C. Cardelino, K. J. Olszyna, and R. G. Zika, Trace gas concentrations and emissions in downtown Nashville during the 995 Southern Oxidants Study/Nashville intensive, J. Geophys. Res., 103, 22,545-22,553, 1998.

Konrad, S., and A. Volz-Thomas, Characterization of a commercial gas chromatography-flam ionization detection system for the in situ determination of $\mathrm{C} 5-\mathrm{C} 10$ hydrocarbons in ambient air, J. Chromatogr. A, 878, 215-234, 2000.

Kramp, F., and A. Volz-Thomas, On the budget of $\mathrm{OH}$ radicals and ozone in an urban plume from the decay of $\mathrm{C}_{5}$ to $\mathrm{C}_{8}$ hydrocarbons and $\mathrm{NO}_{x}$, J. Atmos. Chem., 28, 263-282, 1997.

Kühlwein, J., and R. Friedrich, Uncertainties of modeling emissions from road transport, Atmos. Environ., 34, 4603-4610, 2000.

Kwok, S. C., and R. Atkinson, Estimation of hydroxyl radical reaction rate constants for gas phase organic compounds using a structure-reactivity relationship: An update, Atmos. Environ., 29, 1685-1695, 1995.

Lattuati, M., Contribution à l'étude du bilan de l'ozone troposphérique à l'interface de l'Europe et de l'Atlantique Nord: Modélisation lagrangienne et mesures en altitude, Ph.D. thesis, Univ. Paris VI, France, 1997.

Lehning, M., The regional pollutant budget of the atmospheric boundary layer: Concept, interpretation and observational results, Meteorol. Z., 7, $112-119,1998$
Mannschreck, K., D. Klemp, D. Kley, R. Friedrich, J. Kühlwein, B. Wickert, and F. Slemr, Evaluation of an emission inventory by comparisons of modeled and experimentally derived concentration ratios of individual NMHC, $\mathrm{CO}$ and $\mathrm{NO}_{x}$, Atmos. Environ., 36, 81-94, 2002.

Mendoza-Dominguez, A., and A. G. Russel, Estimation of emission adjustments from the application of four-dimensional data assimilation to photochemical air quality modeling, Atmos. Environ., 35, 2879-2894, 2001.

Menut, L., et al., Measurements and modeling of atmospheric pollution over the Paris area: An overview of the ESQUIF project, Ann. Geophys., 18, 1467-1481, 2000.

Middleton, P., W. R. Stockwell, and W. P. Carter, Aggregation and analysis of volatile organic compound emissions for regional modeling, Atmos. Environ., 24, 1107-1133, 1990.

Neininger, B., W. Fuchs, M. Baeumle, A. Volz-Thomas, A. S. H. Prévôt, and J. Dommen, A small aircraft for more than just ozone: MetAir's DIMONA after ten years of evolving development, paper presented at the 11th Symposium on Meteorological Observations and Instrumentation, Am. Meteorol. Soc., Albuquerque, N. M., 14 - 19 Jan. , 2001.

Ntziachristos, L., and Z. Samaras, COPERT III: Computer programme to calculate emissions from road transport, Tech. Rep. 49, Eur. Environ. Agency, Copenhagen, 2000.

Photochemical Oxidants Review Group (PORG), Ozone in the United Kingdom, 3rd Rep., Harwell Lab., U.K. At. Energ. Auth., Oxfordshire, England, 1993.

Photochemical Oxidants Review Group (PORG), Ozone in the United Kingdom, 4th Rep., Harwell Lab., U.K. At. Energ. Auth., Oxfordshire, England, 1997.

Rudd, H., and I. Marlowe, Improvements to the VOC inventory through speciation of white spirits: A report produced for the department of the environment, transport and the regions, Rep. 3321/20011001, issue 1, AEA Technol., Oxfordshire, England, 1998.

Sallès, J., J. Janischewski, A. Jaecker-Voirol, and B. Martin, Mobile source emission inventory model application to Paris area, Atmos. Environ., 30, 1965-1975, 1996.

Schmidt, H., C. Derognat, R. Vautard, and M. Beekmann, A comparison of simulated and observed ozone mixing ratios for the summer of 1998 in western Europe, Atmos. Environ., 35, 6277-6297, 2001.

Schmitz, T., D. Hassel, and F.-J. Weber, Determination of VOC components in the exhaust of gasoline and diesel passenger cars, Atmos. Environ., 34, 4639-4647, 2000.

Theloke, J., A. Obermeier, and R. Friedrich, Ermittlung der Lösemittelemissionen 1994 in Deutschland und Methoden zur Fortschreibung, in Auftrag des Umweltbundesamtes, Rep. 29542 628, Univ. Stuttgart, Germany, 2000 .

Theloke, J., A. Obermeier, and R. Friedrich, Abschätzung der Lösemittelemissionen in Deutschland, Gefahrstoffe Reinhaltung Luft, 61, 105-111, 2001.

Touaty, M., Développement instrumental de la mesure en continu des hydrocarbures légers par chromatographie en phase gazeuse, Ph.D. thesis, 159 pp., Univ. Paris VII, France, 1999.

Trainer, M., D. D. Parrish, P. D. Goldan, J. Roberts, and F. C. Fehsenfeld, Review of observation-based analysis of the regional factors influencing ozone concentrations, Atmos. Environ., 34, 2045-2061, 2000.

Vautard, R., M. Beekmann, J. Roux, and D. Gombert, Validation of a hybrid forecasting system for the ozone concentrations over the Paris area, Atmos. Environ., 35, 2449-2461, 2001.

M. Beekmann and P. Drobinski, Service d'Aéronomie, Centre National de la Recherche Scientifique, 3A, Avenue de la Recherche Scientifique, F-45072 Orleans-La-Source, France. (Matthias.Beekmann@aero.jussieu. fr; Philippe.Drobinski@1md.polytechnique.fr)

R. Friedrich and J. Theloke, Institute of Energy Economics and the Rational Use of Energy, University of Stuttgart, Heßbrühlstrasse 49a, D-70565 Stuttgart, Germany. (rf@ier.uni-stuttgart.de; jt@ier.uni-stuttgart.de)

A. Jaubertie and M. Lattuati, AIRPARIF, 7 rue Crillon, F-75004 Paris, France. (ajaubertie@airparif.asso.fr; mireille.lattuati@airparif.asso.fr)

D. Kley, Institute for Chemistry of the Polluted Atmosphere, Forschungszentrum, D-52425 Jülich, Germany. (d.kley@fz-juelich.de)

D. Martin, Météo France, 1 Quai Branly, F-75007 Paris, France. (daniel.martin@meteo.fr)

P. Moral, Laboratoire des Sciences du Climat et de 1'Environnement Bât. 709, Orme des Merisiers, F-91191 Gif-sur-Yvette Cedex, France. (morale@1sce.saclay.cea.fr)

B. Neininger, MetAir, Sonnenberg 27, CH-6313 Menzingen, Switzerland. (neininger@metair.ch)

R. Vautard, Laboratoire de Météorologie Dynamique, Ecole Polytechnique, F-91128 Palaiseau cedex, France. (vautard@1md.polytechnique.fr) 